\title{
tRNA base methylation identification and quantification via high-throughput sequencing
}

\author{
WESLEY C. CLARK, ${ }^{1,4}$ MOLLY E. EVANS, ${ }^{1,4}$ DAN DOMINISSINI, ${ }^{2}$ GUANQUN ZHENG, ${ }^{1}$ and TAO PAN ${ }^{1,3}$ \\ ${ }^{1}$ Department of Biochemistry and Molecular Biology, ${ }^{2}$ Department of Chemistry, University of Chicago, Chicago, Illinois 60637, USA \\ ${ }^{3}$ Institute for Biophysical Dynamics, University of Chicago, Chicago, Illinois 60637, USA
}

\begin{abstract}
Eukaryotic transfer RNAs contain on average 14 modifications. Investigations of their biological functions require the determination of the modification sites and the dynamic variations of the modification fraction. Base methylation represents a major class of tRNA modification. Although many approaches have been used to identify tRNA base methylations, including sequencing, they are generally qualitative and do not report the information on the modification fraction. Dynamic mRNA modifications have been shown to play important biological roles; yet, the extent of tRNA modification fractions has not been reported systemically. Here we take advantage of a recently developed high-throughput sequencing method (DM-tRNA-seq) to identify and quantify tRNA base methylations located at the Watson-Crick face in HEK293T cells at single base resolution. We apply information derived from both base mutations and positional stops from sequencing using a combination of demethylase treatment and cDNA synthesis by a thermophilic reverse transcriptase to compile a quantitative "Modification Index" (MI) for six base methylations in human tRNA and rRNA. MI combines the metrics for mutational and stop components from alignment of sequencing data without demethylase treatment, and the modifications are validated in the sequencing data upon demethylase treatment. We identify many new methylation sites in both human nuclear and mitochondrial-encoded tRNAs not present in the RNA modification databases. The potentially quantitative nature of the MI values obtained from sequencing is validated by primer extension of several tRNAs. Our approach should be widely applicable to identify tRNA methylation sites, analyze comparative fractional modifications, and evaluate the modification dynamics between different samples.
\end{abstract}

Keywords: high-throughput sequencing; methylation; modification; quantification; tRNA

\section{INTRODUCTION}

Over 100 types of post-transcriptional RNA modifications have been identified in biology (Grosjean 2005). RNA modifications are a source of cellular and biological tuning of RNA function (Phizicky and Hopper 2010; Wei et al. 2011; Fu et al. 2014; Li and Mason 2014). The most extensively modified cellular RNAs include rRNA and tRNA, each with multifaceted functions. rRNA modifications affect ribosome maturation and numerous aspects of protein synthesis (Decatur and Fournier 2002; Liang et al. 2009; Higa-Nakamine et al. 2012). Mammalian tRNAs are the most highly modified RNA molecule in the cell, containing on average 14 modified nucleotides per molecule, or one modification present for approximately every five residues (Phizicky and Hopper 2010; Cantara et al. 2011; Machnicka et al. 2013; Zheng et al. 2015). tRNA modifications are known to affect all aspects of tRNA biology including decoding and charging efficiency and fidelity, in vivo stability, and intracellular localization

\footnotetext{
${ }^{4}$ These authors contributed equally to this work. Corresponding author: taopan@uchicago.edu

Article published online ahead of print. Article and publication date are at http://www.rnajournal.org/cgi/doi/10.1261/rna.056531.116.
}

(Bjork et al. 1989; Gerber and Keller 1999; Ohira and Suzuki 2011; Whipple et al. 2011; Zaborske et al. 2014). The human tRNAome consists of $~ 500$ tRNA genes distributed among 49 isoacceptors, i.e., tRNAs with different anticodon sequences (Chan and Lowe 2009). Furthermore, each isoacceptor family contains many distinct sequences in the tRNA body, so that $\sim 300$ tRNA sequences are encoded in a human genome (Goodenbour and Pan 2006; Chan and Lowe 2009). These tRNAs may have different modification patterns depending on sequence, anticodon stem-loop context, and other factors. Although it is commonly assumed that many modification sites in tRNA are fully modified, previous literature provides scattered evidence that certain modification sites in specific tRNAs can be fractionally modified (Kuchino et al. 1981; Chan et al. 1982; Saikia et al. 2010; Vinayak and Pathak 2010; Hauenschild et al. 2015), suggesting that dynamic differences in tRNA modification may be a potentially useful parameter for biological regulation.

(C) 2016 Clark et al. This article is distributed exclusively by the RNA Society for the first 12 months after the full-issue publication date (see http://rnajournal.cshlp.org/site/misc/terms.xhtml). After 12 months, it is available under a Creative Commons License (Attribution-NonCommercial 4.0 International), as described at http://creativecommons.org/licenses/by-nc/4.0/. 
Extensive studies have been performed to identify tRNA modifications in a site-specific manner (e.g., Chan et al. 2010; Suzuki and Suzuki 2014). The most common method was to first separate a tRNA of interest from total cellular RNA, followed by digestion to oligonucleotides and the determination of modification site by either thin-layer chromatography (TLC) or liquid chromatography and mass spectrometry (LC/MS). These methods have the ability to access all modification types and have been the standards in establishing the full modification patterns in individual tRNAs. Major drawbacks of these methods are the difficulty and the very large amount of material needed to isolate an individual tRNA from cellular RNA. Another method of identifying tRNA modification sites relies on reverse transcriptase (RT) stops and/or mutations that occur at several specific modification types at the Watson-Crick face of the nucleobase (Motorin et al. 2007; Ryvkin et al. 2013). This "modification-detection-by-synthesis" method can be applied transcriptome-wide for tRNA. However, previous tRNA sequencing methods were inefficient and not quantitative due to the low quality of sequencing reads derived from poorly characterized RT stop and mutation efficiencies at individual modification types and sites. It was also shown that RT stop and mutation are strongly context dependent for a modification type such as $\mathrm{N}^{1}$-methyladenosine $\left(\mathrm{m}^{1} \mathrm{~A}\right)$ (Hauenschild et al. 2015). In TLC, LC/MS, and previous sequencing studies, it has not been feasible to establish quantitative information on tRNA modification fractions at individual sites.

Recent studies on N6-methyladenosine $\left(\mathrm{m}^{6} \mathrm{~A}\right)$ and $\mathrm{N1}$ methyladenosine $\left(\mathrm{m}^{1} \mathrm{~A}\right)$ in mRNAs indicate that dynamic RNA modifications play important biological roles (Dominissini et al. 2012, 2016; Meyer et al. 2012; Li et al. 2016). Dynamic mRNA modification has a cell-type and cell-statedependent pattern that includes the location of the modification sites and the modification fractions at each site. tRNA modifications are generally present in the same locations derived from the specificity of the modification enzymes and tRNA sequence/structure. Therefore, dynamic tRNA modifications would most likely be derived from the variations in the modification fractions at each site. Indeed, a previous study using low-resolution microarrays on $\mathrm{m}^{1} \mathrm{~A} 58$ modification shows that $\mathrm{m}^{1} \mathrm{~A} 58$ sites in some tRNAs are hypomodified (Saikia et al. 2010). Despite previous efforts, the transcriptome-wide method has been lacking to systematically quantify tRNA modifications at single-base resolution.

Recently, our group and Lowe/Phizicky laboratories published Illumina sequencing methods for tRNA: DM-tRNAseq (demethylase tRNA sequencing) and ARM-seq (AlkBfacilitated RNA methylation sequencing) (Cozen et al. 2015; Zheng et al. 2015). The principle of both methods is to use the E. coli AlkB demethylase and its mutant as central components to remove $\mathrm{m}^{1} \mathrm{~A}, \mathrm{~N} 3$-methyl-cytosine $\left(\mathrm{m}^{3} \mathrm{C}\right)$, and N1-methyl-guanosine $\left(\mathrm{m}^{1} \mathrm{G}\right)$ modifications at the Watson-Crick face in tRNA prior to cDNA synthesis.
While the initial results mainly emphasized the increased frequency in the full-length tRNA or tRNA fragment reads due to demethylation, neither publication provided a detailed analysis on the tRNA modification landscape, especially the ability of using tRNA-seq to quantify modification fractions. In our published DM-tRNA-seq results (Zheng et al. 2015), we showed that the application of a thermophilic RT (TGIRT) enabled a large number of reads derived from readthroughs of these modifications. Furthermore, TGIRT leaves a very strong mutation and stop signature for different modification types and sites. However, a thorough analysis on the applicability of the DM-tRNA-seq method on tRNA modifications was not carried out.

Here, we provide a comprehensive, detailed study on applying DM-tRNA-seq to identify specific base methylations as well as to generate quantitative information of modification fractions at these sites in the human tRNA transcriptome. We were able to thoroughly analyze six base methylations in tRNA and rRNA $\left[\mathrm{m}^{1} \mathrm{~A}, \mathrm{~m}^{3} \mathrm{C}, \mathrm{m}^{1} \mathrm{G}, \mathrm{N}^{2}, \mathrm{~N}^{2}\right.$ dimethyl-guanosine $\left(\mathrm{m}_{2}^{2} \mathrm{G}\right)$, 1-methylinosine $\left(\mathrm{m}^{1} \mathrm{I}\right)$, and $\mathrm{N}^{3}$-methyl-uridine $\left(\mathrm{m}^{3} \mathrm{U}\right)$, Fig. 1]. Using known positions of modification in tRNA, we can infer identification of five other modifications [inosine (I), dihydrouridine (D), methyl-2-thio-N6-threonylcarbamoyl-adenosine $\left(\mathrm{ms}^{2} \mathrm{t}^{6} \mathrm{~A}\right)$, methyl-2-thio-N6-isopentenyl-adenosine $\left(\mathrm{ms}^{2} \mathrm{i}^{6} \mathrm{~A}\right), 1$-methyl-3(3-amino-3-carboxypropyl)pseudouridine $\left.\left(\mathrm{m}^{1} \mathrm{acp}^{3} \Psi\right)\right]$. We provide a complete map of the human tRNA transcriptome on four methylations $\left(\mathrm{m}^{1} \mathrm{~A}, \mathrm{~m}^{3} \mathrm{C}, \mathrm{m}^{1} \mathrm{G}, \mathrm{m}_{2}^{2} \mathrm{G}\right)$ in both nuclear and mitochondrial-encoded tRNAs in HEK293T cells, many of which were unknown or unvalidated previously. We apply a quantitative metric, the "Modification Index" (MI), to describe each modification site that includes frequencies of mutations and stops to further characterize the modification landscape in human tRNAs. MI values enable access of quantitative or semiquantitative information regarding the modification levels at individual tRNA positions. We validate the quantitative nature of the MI analysis for several tRNAs by primer extension. Our results establish DMtRNA-seq as a high-throughput method to detect and quantify or semiquantify numerous tRNA modifications and its applicability for the studies of dynamic tRNA modifications.

\section{RESULTS}

\section{Identification of tRNA methylation sites}

Nextgen tRNA sequencing had been difficult to be performed efficiently and quantitatively due to the presence of a large number of base modifications at the Watson-Crick face and the stable tRNA structure. Our laboratory and the Lowe/Phizicky laboratories independently developed tRNAseq methods that first removed many base methylations using AlkB-derived enzymes before cDNA synthesis (Cozen et al. 2015; Zheng et al. 2015). We also used a thermophilic reverse transcriptase (TGIRT) that could more efficiently read 
A
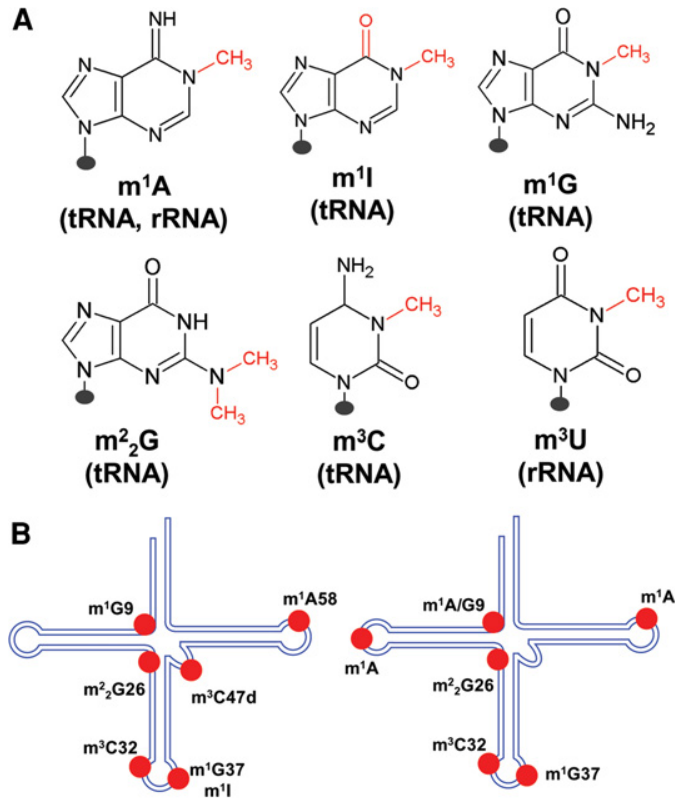

Nuclear-encoded

Mitochondrial-encoded

FIGURE 1. Methylations in human tRNA and rRNA investigated in this study. (A) Chemical structure of the six modifications where the methyl group is shown in red. The presence of each modification in tRNA and/or rRNA is listed beneath each base. (B) Schematic tRNA cloverleaf structure where the methylations for nuclear-encoded $(l e f t)$ and mitochondrial-encoded (right) tRNAs investigated in this work are located.

through base methylations than the commonly used superscript RTs. Hence, more mutation signatures are present in our sequencing data using cellular RNA from HEK293T cells. Our sequencing strategy split each sample into two, one directly sequenced and the other first treated with the demethylase enzymes before cDNA synthesis. In this work, the untreated sequencing data are used for modification analysis, whereas the demethylase-treated sequencing data are used for validating the presence of modifications.

To identify potential sites of modifications that result in RT readthrough mutations and stops, all sequencing reads were aligned to mature tRNA sequences to obtain maximal coverage of modified molecules. A decision tree is shown for the flagged modification indices $\geq 0.15$ at each position (Supplemental Fig. S1). We first look for the effect of demethylase treatment at each flagged site. $\mathrm{m}^{1} \mathrm{~A}, \mathrm{~m}^{3} \mathrm{C}, \mathrm{m}^{1} \mathrm{G}$, $\mathrm{m}_{2}^{2} \mathrm{G}$, and $\mathrm{m}^{3} \mathrm{U}$ sites show decreased MI values upon demethylase treatment (left branch). Sites that are unaffected by demethylase treatment are further assessed based on whether the MI is composed of only mutations, only stops, or a mixture of mutations and stops (right branch). Among the right branch, mutations only correspond to A-to-inosine modification or isodecoder misalignment, stops only correspond to the presence of bulky modifications in the Watson-Crick face and dihydrouridine (D), and a mixture of mutations and stops corresponds to other, uncommon modifications in the Watson-Crick face. This type of analysis enables us to identify the specifics of the modification using the MI values.

Biological tRNAs are made of type I's which have a 4-5 nucleotide (nt) variable loop, and type II's which have a longer variable loop that folds into a short hairpin. We plotted the cumulative MI for all type I tRNAs comprised of 18 of the 20 amino acids, and type II tRNA comprised of the amino acids leucine and serine (Fig. 2A). For type I tRNAs, high MI peaks are apparent around nucleotides 58, 37, 34, 26, 20, 9, and 4-7. Upon demethylase treatment, MI values are reduced to near background levels for the peak around $58,>50 \%$ for the peak around 37, and moderately reduced for the peak around 9. As we have already shown previously (Zheng et al. 2015), this result validates the peaks around position 58 as $\mathrm{m}^{1} \mathrm{~A} 58,37$ as $\mathrm{m}^{1} \mathrm{G} 37,9$ as $\mathrm{m}^{1} \mathrm{G} 9 ; \mathrm{m}^{1} \mathrm{~A}$ and $\mathrm{m}^{1} \mathrm{G}$ are known tRNA modification targets of the AlkB and AlkBD135S enzymes used in the sequencing experiment. The same conclusion can be applied to the type II tRNAs for the peak around 67 as $\mathrm{m}^{1} \mathrm{~A}$ at the same location as $\mathrm{m}^{1} \mathrm{~A} 58$ in the type I tRNA, $50 \mathrm{as} \mathrm{m}^{3} \mathrm{C}$ located in the loop of the variable loop hairpin $\left(\mathrm{m}^{3} \mathrm{C} 47 \mathrm{~d}\right.$ in the standard tRNA nomenclature), 37 as $\mathrm{m}^{1} \mathrm{G} 37,32$ as $\mathrm{m}^{3} \mathrm{C} 32$, and 9 as $\mathrm{m}^{1} \mathrm{G}$. As expected from known tRNA modifications, some positions are not affected by demethylase treatment including the peak around 34 as inosine, around 20 that can be found commonly in tRNAs containing two consecutive dihydrouridines in the D loop.

The demethylase treatment significantly reduced the MI values of the $\mathrm{m}^{1} \mathrm{G} 37$ peak, but only moderately reduced the MI value of the $\mathrm{m}^{1} \mathrm{G} 9$ peak, even though both are made of the same chemical structure (Fig. 2A). This result can be interpreted as the extent of tRNA structure interfering with the demethylase reaction: $\mathrm{m}^{\mathrm{l}} \mathrm{G} 37$ is located in the anticodon loop and easily accessible to the demethylase enzyme, whereas $\mathrm{m}^{1} \mathrm{G} 9$ forms a base triple with the 23-12 base pair of the $\mathrm{D}$ stem and is much more buried. Our demethylase enzyme reactions were performed under conditions where the modified tRNAs are still folded. At this time, the demethylase treatment cannot yet be performed under conditions where modified tRNAs are denatured which would require the removal or chelation of all divalent metal ions. The demethylase enzymes require divalent metal ions for their enzymatic activity.

Interestingly, the demethylase reaction also slightly reduced the MI values of the type II tRNAs at the peak around 26 , corresponding to $\mathrm{m}_{2}^{2} \mathrm{G} 26$ modifications. This result suggests that our demethylase mixture is also reactive toward the $\mathrm{m}_{2}^{2} \mathrm{G} 26$ modification. $\mathrm{m}_{2}^{2} \mathrm{G} 26$ pairs with nucleotide 44 , and this pair is sandwiched between the D and the anticodon stems, making it even less accessible than $\mathrm{m}^{1} \mathrm{G} 9$ which may explain the poor reactivity of the demethylase toward the $\mathrm{m}_{2}^{2} \mathrm{G} 26$ modification.

We further plotted the two parameters that compose the MI values, mutation fraction and stop fraction, separately for the cumulative type I and II tRNAs (Fig. 2B,C). Dominant mutations are all attributed to the four known types and 

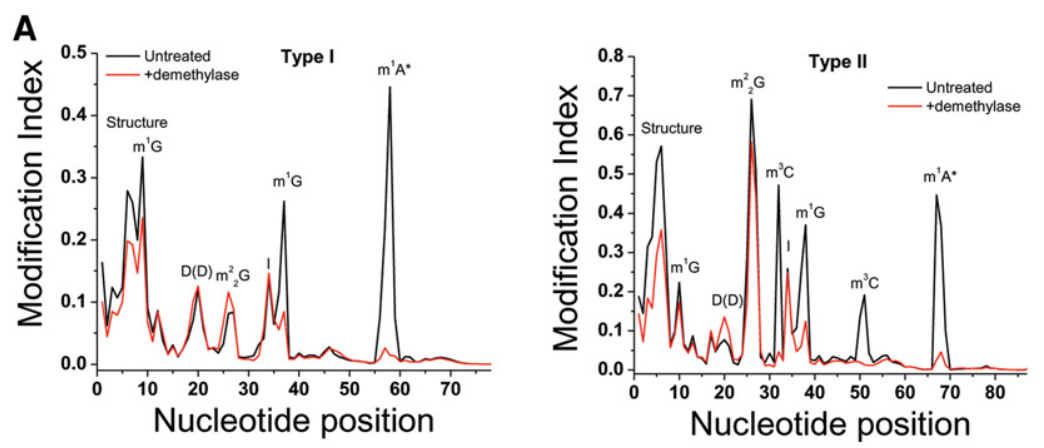

modified nucleotides in the RNA template, or some kind of RNA-cDNA structure effects. Reverse transcriptase stops at $\mathrm{m}^{1} \mathrm{~A} 58$ are likely underestimated in this sequencing data set due to the short cDNA products generated that can be missed in the sequencing reaction.

A representative example of how MI, mutation, and stop fraction plots look for a specific tRNA with multiple methylations at $\mathrm{W}-\mathrm{C}$ face is shown in Figure $3 \mathrm{~A}$. In these graphs, the $x$-axis designates the nucleotide position and the $y$-axis the fraction of mutated and stopped (left panel), just mutated (middle), or just stopped (right) reads aligned to each position in this tRNA, LeuCAG isodecoder from chromosome 1, tRNA34 (CAGc1t34) according to the hg19 genomic tRNA database (Chan and Lowe 2009). Because of the background, we choose to interpret only these peaks with an MI value $\geq 0.15$ as a confidence threshold (dashed line in Fig. 3A). Three known methylations, $\mathrm{m}^{1} \mathrm{~A}, \mathrm{~m}^{1} \mathrm{G}$, and $\mathrm{m}_{2}^{2} \mathrm{G}$ (Fig. 3B) can be readily identified from these graphs that all have reduced MI values upon demethylase treatment. The large stop peak toward the $5^{\prime}$ end of the tRNA is likely derived from difficulties of RT retaining processivity as discussed for the cumulative type I and type II plots (Fig. 2C).

For LeuCAG, we found another peak located at C47d that was also removed upon demethylase treatment, consistent with a previously unidentified $\mathrm{m}^{3} \mathrm{C}$ at this position. We also found an unknown adenosine modification at position 9 in AspGTC (Fig. 3C). For position 9 modilocations of base methylations in tRNA, $\mathrm{m}^{1} \mathrm{~A}, \mathrm{~m}^{1} \mathrm{G}, \mathrm{m}^{2}{ }_{2} \mathrm{G}$, and $\mathrm{m}^{3} \mathrm{C}$, as well as the well-known A34 to inosine modifications. Dominant stops are attributed to the known $\mathrm{m}^{1} \mathrm{G}$, $\mathrm{m}_{2}^{2} \mathrm{G}, \mathrm{m}^{3} \mathrm{C}, \mathrm{ms}^{2} \mathrm{t}^{6} \mathrm{~A}$, and consecutive dihydrouridine (DD) modifications. Strong stops are present around nucleotides 4-7, which are moderately reduced upon demethylase treatment. This region is not known to be modified; yet the RT appears to fall off frequently during cDNA synthesis. At this time, we do not understand why these stops are present. In some cases, it is likely due to the presence of $\mathrm{m}^{1} \mathrm{G} 9$ in the RNA template of the RT reaction, since removal of $\mathrm{m}^{1} \mathrm{G} 9$ by demethylase prior to cDNA synthesis simultaneously reduces the extent of stops in this region (see the graph for several mitochondrial tRNAs in Fig. 3D,E). In other cases, it may be due to a reduction of RT processivity after encountering many fications in human tRNA, $\mathrm{m}^{1} \mathrm{G} 9$ is common among cytoplasmic tRNAs, whereas $\mathrm{m}^{1} \mathrm{~A} 9$ is common among mitochondrial tRNAs. We were surprised to find that the cytoplasmic tRNA $^{\text {Asp }}$ also contains a modification that responded to demethylase treatment, which is consistent with an $\mathrm{m}^{1} \mathrm{~A}$ modification. We performed additional experiments to independently validate these two new methylation sites (see below).

In order to validate the usefulness of our alignment strategy with respect to available aligners, we compared mapping using either Bowtie1 or Bowtie2 aligner (Supplemental Fig. S2). A major difference between Bowtiel and Bowtie2 is that Bowtie2 allows for insertions and deletions (indels). For the highly abundant tRNAs shown in Supplemental Figure S2, the modification sites are easily identified with 
A

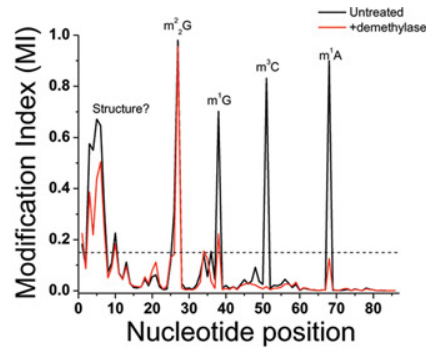

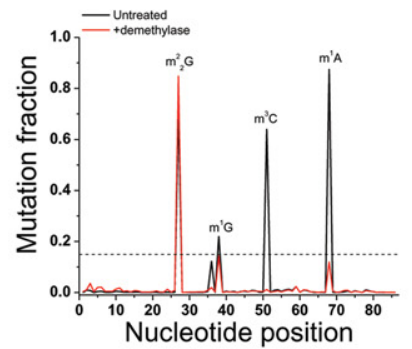

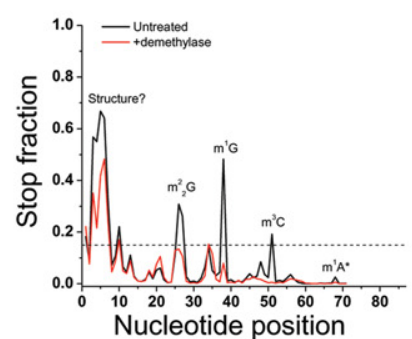

B

>Homo_sapiens_Leu-CAG-1-1 (chr1.trna34-LeuCAG)

GTCAGGATGGCCGÄGCGGTCTAAGGC $\left(\mathrm{m}^{2}{ }_{2} \mathrm{G}\right)$ CTGCGTTCAG $\left(\mathrm{m}^{1} \mathrm{G}\right)$ TCGCAGTCTCCC $\left(\mathrm{m}^{3} \mathrm{C}\right)$ TGGAGGCGTGGGTTCG $\left(\mathrm{m}^{1} \mathrm{~A}\right)$ ATCCCACTCCTGACACCa
$1(1)(1) \quad(1)$
))
( ( ( 1
)$))) \quad((($
)$)) \quad((()$
1)1)11)11)11

C

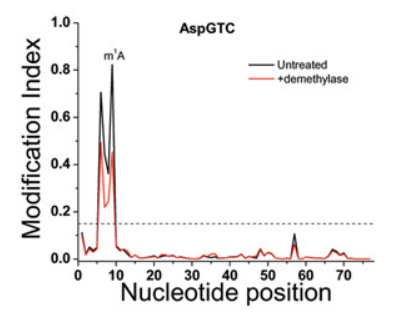

D

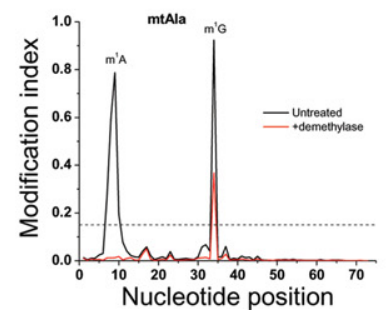

E

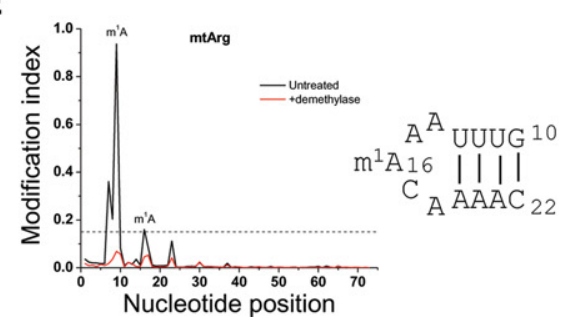

FIGURE 3. Plots for individual tRNAs with known and unknown methylations. (Black line) Untreated; (red line) demethylase-treated samples. Dashed line shows the MI value of $15 \%$ which we use here as the threshold for detectable modifications with high confidence. (A) LeuCAG c1t34 (chromosome 1, tRNA34) isodecoder contains all four demethylase reactive modifications of $\mathrm{m}^{1} \mathrm{~A}, \mathrm{~m}^{3} \mathrm{C}, \mathrm{m}^{1} \mathrm{G}$, and $\mathrm{m}^{2}{ }_{2} \mathrm{G}$. MI plot is on the left, mutation plot in the middle, and stop plot on the right. (B) LeuCAG c1t34 sequence with annotated modifications identified in panel $A$. The brackets mark the acceptor, $\mathrm{D}$, anticodon, and T stems of this tRNA. (C) MI plot of AspGTC showing a newly identified $\mathrm{m}^{1} \mathrm{~A} 9$ modification. $(D)$ MI plot of mitochondrial tRNA ${ }^{\text {Ala }}$ showing a newly identified $\mathrm{m}^{1} \mathrm{G} 37$ modification. (E) MI plot of mitochondrial $\mathrm{RRNA}^{\mathrm{Arg}}$ showing a newly identified $\mathrm{m}^{1} \mathrm{~A}$ modification in the D loop whose sequence is also shown.

both alignment programs. The alignments using Bowtie2 seem to be a little noisier than the alignments using Bowtie1, which may be in part derived from the presence of a small amount of indels shifting the mapped positions as arbitrary misincorporations.

We also adjusted for the number of mismatches in the seed sequence, or $v=0,1,2$, and 3 mismatches, a common feature in the Bowtie1 aligner (Supplemental Fig. S3). Allowing for fewer mismatches reduced the overall number of reads due to the abundant mutations located close to the $3^{\prime}$ end of tRNAs such as $m^{1} A 58$. However, even for a heavily modified tRNA such as the LeuCAG, we were able to analyze MIs at $v=$ 2, 3 mismatches. Comparing the MI for the Bowtiel maps relative to the indel-containing Bowtie2 maps also showed a relatively small difference in MI across all of the modifications. Average MI across these highly abundant tRNAs also did not change significantly, nor were there any substantial differences in the plots for cumulative MI across the whole tRNA. These results gave us confidence in the method of alignment and further analysis.

\section{Validation of $m^{1} \mathrm{~A} 9$ in tRNA ${ }^{\text {Asp }}$ (AspGTC) and $\mathbf{m}^{3} \mathrm{C} 47 \mathrm{~d}$ in TRNA ${ }^{\text {Leu }}$ (LeuCAG)}

We performed additional experiments to validate the two new modifications at A9 in AspGTC and C47d in LeuCAG.
Since the sequencing was performed using reverse transcription, we made every effort to avoid any RT reaction in our validation.

For AspGTC, our approach was to use an AspGTC-specific oligo and RNase $\mathrm{H}$ cleavage to first isolate the $5^{\prime}$ fragments of the AspGTC RNA from gel purified total tRNA from HEK293T cells, followed by nuclease T1 digestion to detect a modified fragment containing A9 by MALDI or nuclease $\mathrm{P} 1$ and alkaline phosphatase treatment to detect a methylated A residue by LC-MS (Supplemental Fig. S4A). We tested a variety of conditions and applied the most stringent condition for fragment isolation (Supplemental Fig. S4B). We detected all three expected nuclease T1 fragments in the MALDI assay, including the UUAG/UU(A*)G peaks that differ by $15 \mathrm{Da}$, indicating a presence of a methyl group (Supplemental Fig. $\mathrm{S} 4 \mathrm{C}$ ). We also readily detected $\mathrm{m}^{1} \mathrm{~A}$ using the established QQQ LC-MS method for $\mathrm{m}^{1} \mathrm{~A}$ RNA methylation studies (Supplemental Fig. S4D; Dominissini et al. 2016). These results, together with the mutation and stop signatures at this position (Supplemental Fig. S4E), indicate that the modified A9 residue in AspGTC corresponds to N1-methyladenosine.

For LeuCAG, we also used the approach of isolating RNase H cleaved LeuCAG fragments from gel purified total tRNA from HEK293T cells, followed by nuclease P1 and alkaline phosphatase treatment to specifically identify $\mathrm{m}^{3} \mathrm{C}$ (Supplemental Fig. S5A). Again, stringent RNase H cleavage 
conditions were used to obtain LeuCAG fragments (Supplemental Fig. S5B), and QQQ LC-MS showed the appropriate amount of $\mathrm{m}^{3} \mathrm{C}$ as well as $\mathrm{m}^{1} \mathrm{~A}$ (from $\mathrm{m}^{1} \mathrm{~A} 58$ of LeuCAG) from the isolated fragments (Supplemental Fig. S5C). We also utilized an $\mathrm{m}^{3} \mathrm{C}$-specific base chemistry to validate the LeuCAG site (Supplemental Fig. S5D). Hydrazine reacts with 3-methylcytosine and renders the site abasic, which can be detected as a strand scission after aniline treatment (Peattie 1979; Behm-Ansmant et al. 2011). Using $3^{\prime}{ }^{32} \mathrm{P}$-labeled total tRNA from HEK293T cells, hydrazine/aniline treatment yielded three major fragments that are consistent with the cleavage products of tRNA ${ }^{\text {Ser }}$ at $\mathrm{m}^{3} \mathrm{C} 32$, $\mathrm{tRNA}^{\mathrm{Thr}}$ at $\mathrm{m}^{3} \mathrm{C} 32$, and $\mathrm{tRNA}{ }^{\text {Ser }}$ at $\mathrm{m}^{3} \mathrm{C} 47 \mathrm{~d}$, and the LeuCAG site at $\mathrm{m}^{3} \mathrm{C} 47 \mathrm{~d}$ (Supplemental Fig. S5E; Parisien et al. 2013). These specific tRNA products were confirmed by tRNA microarrays (Supplemental Fig. S5F). These results, together with the mutation and stop signatures at this position (Supplemental Fig. S5G), indicate that the modified C47d residue in LeuCAG corresponds to N3-methylcytosine.

\section{Assessment of quantification of methylation fractions}

We calculated the MI value for all tRNA isodecoders among the top 25\% expressed tRNAs according to the number of aligned reads in the untreated sample. Our DM-tRNA-seq data are of sufficient quality that the mapped reads for each of these top quartile tRNAs range from 20,000 to 700,000. Although the MI values can be precisely measured, there are several inherent caveats to interpret these as the precise modification fraction. In particular, the reverse transcription-based method is prone to underestimate the modification fraction to varying degrees in a context-dependent manner (Ryvkin et al. 2013; Hauenschild et al. 2015). In our case, this underestimation can be derived from either the inadequacy of RT stops or the ability of RT to also incorporate the correct nucleotide opposite to the modified base. The $\mathrm{m}^{1} \mathrm{~A} 58$ stop fraction is likely underestimated in our sequencing data; these RT stop reads are only 18 residues and can be easily missed in our experimental design which was aimed for sequencing longer RT products. This effect may be mitigated in future experiments by expanding the size range of RT products to be sequenced. The quantitative variation of incorporating the correct nucleotide, however, is a large obstacle in obtaining strictly quantitative information as this effect can be highly dependent on the chemical structure and the sequence context of the modified base (Hauenschild et al. 2015). For these reasons, the MI values cannot yet be used to fully represent the precise modification fraction without further study. In this work, we choose to group the MI values in three regimes $(0.15-0.50,0.50-0.80$, and 0.80 $1.0)$ as a semiquantitative metric for ease of description and discussion. Table 1 shows the MI groups of four methylation types in the tRNA transcriptome.

$\mathrm{m}^{1} \mathrm{~A} 58$ : Forty of $46(87 \%)$ sites are in the high group, suggesting that most tRNAs are fully modified at this position.
Aside from AspGTC tRNA with $\mathrm{MI}<0.15$ (Fig. 3C), the only other tRNA in the low group is GluCTC. Both Asp and Glu tRNA results are consistent with literature (Kuchino et al. 1981; Chan et al. 1982) that these tRNAs are hypomodified at $\mathrm{m}^{1} \mathrm{~A} 58$. We also validate the low $\mathrm{m}^{1} \mathrm{~A} 58$ modification in tRNA $^{\text {Asp }}$ by primer extension (Fig. 4 below). As described above, we were unable to obtain stop information for the $\mathrm{m}^{1} \mathrm{~A} 58$ modifications in the previous sequencing experiment.

The only other tRNA of note in this group is the initiator tRNA (Met-i) with MI value of 0.77 without the consideration of stops. In yeast, $\mathrm{m}^{1} \mathrm{~A} 58$ is known to be required for the stability of the initiator-tRNA, but not for other tRNAs (Kadaba et al. 2004). It is possible that $\mathrm{m}^{1} \mathrm{~A} 58$ is also required for Met-i stability in mammalian cells. If this is the case, the MI of 0.77 is close to the high regime $(\geq 0.80)$, so Met-i could still be fully modified in HEK293T cells.

$\mathrm{m}^{1} \mathrm{G} 37$ : Nine of $15(60 \%)$ sites are high. This modification is known to prevent ribosome frameshifting in specific tRNA and codon contexts (Bjork et al. 1989; Gamper et al. 2015), so high levels of modifications are expected. Surprisingly, six of 15 tRNAs are in the intermediate and low groups. This result is not fully consistent with the known function $\mathrm{m}^{1} \mathrm{G} 37$ modification. It may be derived from the strong context dependence of incorporating higher fractions of correct nucleotides opposite the $\mathrm{m}^{1} \mathrm{G}$ in these particular tRNAs.

$\mathrm{m}_{2}^{2} \mathrm{G} 26$ : Without exception, all 25 sites belong to the high group. This modification is known to provide rigidity of the coaxially stacked D and anticodon stems (Steinberg and Cedergren 1995) and to prevent misfolding of at least one tRNA (Edqvist et al. 1995; Pallan et al. 2008). Full modification at these sites would ensure that these tRNAs all have proper conformations and rigidity for translation.

$m^{1}$ G9: Fifteen of 19 (79\%) sites are high. This modification is known to play a role in maintaining the structure of mitochondrial tRNAs and possibly cytosolic tRNAs as well (Helm et al. 1999). Hence, the modification fraction is expected to be high for most of these tRNAs.

$\mathrm{m}^{1} \mathrm{~A}$ 9: To our surprise, AspGTC (Fig. 3B) has a high MI at position 9 which is reduced upon demethylase treatment, suggesting the presence of $\mathrm{m}^{1} \mathrm{~A} 9$ modification which we validated by mass spectrometry (Supplemental Fig. S4) and by primer extension below. $\mathrm{m}^{1} \mathrm{~A} 9$ is not known previously to be present in cytosolic tRNAs, but is common among mitochondrial-encoded tRNAs (Suzuki and Suzuki 2014).

$\mathrm{m}^{3} \mathrm{C}$ : These include nine sites at $\mathrm{C} 32$, of which only one is in the high group (11\%); among the five sites at C47d located in the loop region of the hairpin in the variable arm of type II tRNAs, only one is in the high group (20\%); the single site at C20 in the elongator tRNA ${ }^{\text {Met }}$, also predicted by HAMR analysis (Ryvkin et al. 2013) is in the high group. The functions of these $\mathrm{m}^{3} \mathrm{C}$ modifications are unclear; they may perform structural roles for tRNA. However, the prevalence of many $\mathrm{m}^{3} \mathrm{C} 32$ and $\mathrm{m}^{3} \mathrm{C} 47 \mathrm{~d}$ modifications present in the low and intermediate groups suggests that $\mathrm{m}^{3} \mathrm{C}$ modification fractions may be useful for regulatory purposes. 
TABLE 1. Methylations identified in the human tRNAome by DM-tRNA-seq

\begin{tabular}{|c|c|c|c|c|c|}
\hline $\mathrm{tRNA}^{\mathrm{a}}$ & $\mathrm{m}^{1} \mathrm{~A} 58^{\mathrm{b}, \mathrm{c}}$ & $\mathrm{m}^{1} \mathrm{G} 37^{\mathrm{b}}$ & $\mathrm{m}_{2}^{2} \mathrm{G} 26^{\mathrm{b}}$ & $m^{1} G 9^{b}$ & $m^{3} C^{b}$ \\
\hline AlaAGC & +++ & & +++ & & \\
\hline AlaCGC & $++^{d}$ & & +++ & & \\
\hline AlaTGC & $++^{d}$ & & +++ & & \\
\hline CysGCA & $+++^{\mathrm{d}}$ & +++ & & & \\
\hline AspGTC & e & & & $+++(A)$ & \\
\hline GluCTC & + & & & + & \\
\hline GluTTC & ++ & & & ++ & \\
\hline PheGAA &,$++++(14)$ & & +++ & & \\
\hline GlyCCC & +++ & & & & \\
\hline GlyGCC & +++ & & & & \\
\hline GlyTCC & +++ & & & & \\
\hline HisGTG & +++ & ++ & & & \\
\hline IleAAT & +++ & & +++ & & \\
\hline IleTAT & $+++{ }^{d}$ & & +++ & +++ & \\
\hline LysCTT & +++ & & & & \\
\hline LysTTT & +++ & & & & \\
\hline LeuAAG & +++ & + & +++ & & \\
\hline LeuCAG & +++ & ++ & +++ & & $+++(47 d)$ \\
\hline LeuTAG & +++ & + & +++ & & \\
\hline LeuCAA & +++ & +++ & +++ & & \\
\hline LeuTAA & +++ & +++ & +++ & & \\
\hline Met-i & $++^{f}$ & & & +++ & \\
\hline Met-e & +++ & & +++ & & $+++(20)$ \\
\hline AsnGTT & +++ & & +++ & +++ & \\
\hline ProAGG & +++ & ++ & & +++ & \\
\hline ProCGG & +++ & ++ & & +++ & \\
\hline ProTGG & +++ & +++ & & +++ & \\
\hline GlnCTG & +++ & & & +++ & \\
\hline GInTTG & +++ & & & +++ & \\
\hline ArgACG & +++ & +++ & +++ & +++ & \\
\hline ArgCCG & +++ & +++ & +++ & +++ & \\
\hline ArgTCG & $+++{ }^{d}$ & +++ & +++ & +++ & \\
\hline ArgCCT & +++ & & & +++ & $+(32)$ \\
\hline ArgTCT & +++ & & & +++ & $++(32)$ \\
\hline SecTCA & +++ & & & & \\
\hline SerAGA & +++ & & +++ & & $++(32)+(47 d)$ \\
\hline SerCGA & $+++{ }^{d}$ & & +++ & & $++(32)+(47 d)$ \\
\hline SerTGA & +++ & & +++ & & $+++(32)+(47 d)$ \\
\hline SerGCT & +++ & & +++ & & $++(32),++(47 \mathrm{~d})$ \\
\hline ThrAGT & +++ & & +++ & ++ & $++(32)$ \\
\hline ThrCGT & +++ & & +++ & +++ & $++(32)$ \\
\hline ThrTGT & +++ & & +++ & +++ & $++(32)$ \\
\hline ValAAC & ++ & & & & \\
\hline ValCAC & +++ & & & & \\
\hline ValTAC & +++ & & & & \\
\hline TrpCCA & +++ & +++ & +++ & ++ & \\
\hline TyrGTA & +++ & +++ & +++ & & \\
\hline
\end{tabular}

${ }^{a}$ Not bold, known in human or other mammalian tRNA (10). Bold, previously unknown in human and other mammalian tRNA.

$\mathrm{b}_{(+)} \mathrm{Ml}=0.15-0.50 ;(++) \mathrm{Ml}=0.50-0.80 ;(+++) \mathrm{Ml}=0.80-1.0$.

${ }^{\mathrm{C}} \mathrm{MI}$ values for $\mathrm{m}^{1} \mathrm{~A} 58$ include mutations only.

${ }^{\mathrm{d}}$ Also described in Cozen et al. (2015) (32).

${ }^{e} \mathrm{~m}^{1} \mathrm{~A}$ is still present as validated by primer extension (Fig. 4B). The MI value is 0.11 in untreated and 0.06 in demethylase-treated data.

${ }^{\mathrm{f}} \mathrm{MI}$ value is 0.77 , close to the boundary of the high group (0.80).

We also analyzed the modification indexes for the $22 \mathrm{hu}-$ man mitochondrial tRNAs (Table 2). The complete mitochondrial tRNA modifications have been mapped in the bovine liver (Suzuki and Suzuki 2014), and several human mitochondrial tRNA modifications are also known (Machnicka et al. 2013). We were able to detect all 19 expected $\mathrm{m}^{1} \mathrm{~A} / \mathrm{G} 9$ modifications, and 16 of 19 (84\%) belong to the high MI group. $\mathrm{M}^{1} \mathrm{~A} / \mathrm{G} 9$ in mitochondrial tRNAs are very efficiently removed by the demethylases (Fig. 3C,D), presumably due to the lower structural stability of mitochondrial versus cytosolic tRNAs. On the basis of the bovine mitochondrial tRNA modifications, we detected $\mathrm{m}^{1} \mathrm{~A} 58$ or equivalent in mtLeu(TAA), mtLys, and mtSer (TGA), but not in mtGlu, mtlle, and mtCys. We detected all three $\mathrm{m}^{1} \mathrm{G} 37$ modifications in mtGln, mtLeu(TAG), mtPro, $\mathrm{m}_{2}^{2} \mathrm{G} 26$ in mtIle, $\mathrm{m}^{3} \mathrm{C} 32$ in $\mathrm{mtSer}(\mathrm{TGA})$, and $\mathrm{mtThr}$, as predicted from bovine mt-tRNAs.

We also found three new mitochondrial tRNA modifications that could not be inferred from the bovine mitochondrial tRNAs. Human mtAla has a G after the anticodon UGC, and this G is highly modified to $\mathrm{m}^{1} \mathrm{G}$ (Fig. 3D). We also observed above threshold MI values for G26 in mtAsn, which could be modified to $\mathrm{m}_{2}^{2} \mathrm{G}$ and A16 in mtArg which could be modified to $\mathrm{m}^{1} \mathrm{~A}$ (Fig. 3E).

\section{MI value correlations by primer extension}

We applied the standard primer extension method to correlate the quantitative nature of the MI values in assessing tRNA methylations (Fig. 4). Primer extension relies on using retroviral reverse transcriptases such as AMV RT that stop at methylated nucleotides such as $\mathrm{m}^{1} \mathrm{~A}$. Our experimental design involves a primer that ends $1 \mathrm{nt}$ away from the modification site such as $\mathrm{m}^{1} \mathrm{~A} 58$ (Supplemental Fig. S6). Primer extension reaction is visualized by using the appropriate $\mathrm{a}^{32} \mathrm{P}-\mathrm{dNTP}$ incorporated at position 59. When the reaction mixture contains three dNTPs and one specific ddNTP, the short reaction product corresponds to the stops at the modified nucleotide, and the long reaction product corresponds to the amount of unmodified tRNA. In this way, we validated the presence and the correlation of MI values from sequencing of $\mathrm{m}^{1} \mathrm{~A} 9$ in AspGTC tRNA (Fig. 4A), as well as the low fraction of $\mathrm{m}^{1} \mathrm{~A} 58$ in AspGTC (Fig. 4B). We 
TABLE 2. Methylations identified in the human mitochondrial tRNA by DM-tRNA-seq

\begin{tabular}{|c|c|c|c|c|c|}
\hline $\mathrm{tRNA}^{\mathrm{a}}$ & $m^{1} \mathrm{~A} 58^{\mathrm{b}, \mathrm{c}}$ & $m^{1} \mathrm{G} 37^{b}$ & $\mathrm{~m}_{2}^{2} \mathrm{G} 26^{\mathrm{b}}$ & $\begin{array}{c}\mathrm{m}^{1} \mathrm{~A} \\
\mathrm{G} 9^{\mathrm{b}}\end{array}$ & Other $^{b}$ \\
\hline mtAlaTGC & & {$[+++]$} & & ++ & \\
\hline mtArgTCG & & & & +++ & {$[+]\left(m^{1} \mathrm{~A} 16\right)$} \\
\hline mtAsnGTT & & & {$[+]$} & +++ & \\
\hline mtAspGTC & & & & +++ & \\
\hline mtCysGCA & & & & ++ & \\
\hline mtGlnTTG & & +++ & & +++ & \\
\hline mtGluTTC & & & & +++ & \\
\hline mtGlyTCC & & & & +++ & \\
\hline mtHisGTG & & & & +++ & \\
\hline mtlleGAT & & & +++ & +++ & \\
\hline mtLeuTAA & +++ & & & +++ & \\
\hline mtLeuTAG & & ++ & & +++ & \\
\hline mtLysTTT & + & & & +++ & \\
\hline mtMetCAT & & & & & \\
\hline mtPheGAA & & & & ++ & \\
\hline mtProTGG & & +++ & & +++ & \\
\hline mtSerGCT & & & & & \\
\hline mtSerTGA & + & & & & $+\left(m^{3} \mathrm{C} 32\right)$ \\
\hline mtThrTGT & & & & +++ & $++\left(m^{3} \mathrm{C} 32\right)$ \\
\hline mtTrpTCA & & & & +++ & \\
\hline mtTyrGTA & & & & +++ & \\
\hline mtValTAC & & & & +++ & \\
\hline
\end{tabular}

a(Not bold) Known in human mitochondrial tRNA (10). (Bold) Previously unknown in human and other mammalian mitochondrial tRNA, but can be inferred from the modification maps of bovine mitochondrial tRNAs (25). (In square brackets) New modifications in human mitochondrial tRNA

${ }^{b}(+) \mathrm{MI}=0.15-0.50 ;(++) \mathrm{MI}=0.50-0.80 ;(+++) \mathrm{MI}=0.80-1.0$

${ }^{\mathrm{c}} \mathrm{MI}$ values for $\mathrm{m}^{1} \mathrm{~A} 58$ include mutations only.

also correlated the MI values for $\mathrm{m}^{1} \mathrm{~A} 58$ of GlyGCC tRNA, a tRNA known to have $\mathrm{m}^{1} \mathrm{~A} 58$ in the Modomics database and of ArgTCG tRNA, a tRNA not present in the Modomics database.

In all four cases, the modification indices obtained by primer extension and sequencing are similar (Fig. 4C). The MI values from DM-tRNA-seq seem to slightly underestimate the MI values from AMV RT primer extension by up to $\sim 10 \%$. For $\mathrm{m}^{1} \mathrm{~A} 58$, this result may be derived from the under-counting of reads derived from RT stops at this position in our sequencing data, as discussed above. Our results clearly confirm the very low $\mathrm{m}^{1} \mathrm{~A} 58$ modification levels of AspGTC at $\sim 12 \%$, as well as the presence of $\mathrm{m}^{1} \mathrm{~A} 9$ in AspGTC. These results indicate that the MI values from DM-tRNA-seq are excellent parameters for estimating modification fractions.

\section{Other modifications}

We also looked for peaks with $>15 \%$ MI values that do not change upon demethylase treatment (Fig. 5). AlaAGC is known to contain two inosine modifications at 34 (first anticodon nucleotide) and 37, and three W-C face methylations at $\mathrm{m}^{1} \mathrm{~A} 58, \mathrm{~m}^{1} \mathrm{I} 37$, and $\mathrm{m}_{2}^{2} \mathrm{G} 26$ (Grosjean et al. 1996; Machnicka et al. 2013). I34 is readily apparent in the muta- tion graph as essentially $100 \%$ of this residue has been converted from $A$ to $I$, which reads as $G$, and it does not respond to demethylase treatment (Fig. 5B). $\mathrm{m}^{1} \mathrm{~A} 58$ and $\mathrm{m}_{2}^{2} \mathrm{G} 26$ can be easily picked out due to the reduction in peak height upon demethylase treatment. $\mathrm{m}^{1} \mathrm{I} 37$ leads to mostly stops in the untreated sample; demethylase fully removes the methyl group so that the RT stop is fully eliminated; at the same time, the mutation fraction goes up to nearly $100 \%$ because of the A37 to I conversion. AsnGTT is known to contain two consecutive dihydrouridines in the D-loop (Machnicka et al. 2013). Each D modification is known to weaken $\mathrm{W}-\mathrm{C}$ base pairing by $\sim 1 \mathrm{kcal} / \mathrm{mol}$ (Dalluge et al. 1996), so that the presence of two consecutive D's leads to strong RT stops that do not respond to demethylase treatment (Fig. 5C). LysTTT is known to contain a bulky modification, 2-methylthio-6-threonylcarbamoyl- $\mathrm{A}\left(\mathrm{ms}^{2} \mathrm{t}^{6} \mathrm{~A}\right)$ at A37 (Machnicka et al. 2013). This modification leads to an $\sim 98 \%$ stop in the RT reaction which does not respond to the demethylase treatment (Fig. 5D). Because we are starting out with $\sim 300,000$ reads for this tRNA (Fig. 5D inset), we are still able to obtain $\sim 6000$ reads that process past the modification, and we can assess potential modifications upstream of $\mathrm{ms}^{2} \mathrm{t}^{6} \mathrm{~A} 37$ after this strong stop. Mitochondrial tRNA ${ }^{\mathrm{Tyr}}$ is known to contain another bulky modification, 2-methylthio-6-isopentenyl-A ( $\left.\mathrm{ms}^{2} \mathrm{i}^{6} \mathrm{~A}\right)$ at A37 (Machnicka et al. 2013). This modification leads to an $~ 95 \%$ stop in the RT reaction which does not respond to the demethylase treatment (Fig. 5E). Similarly, the high number of read counts for this
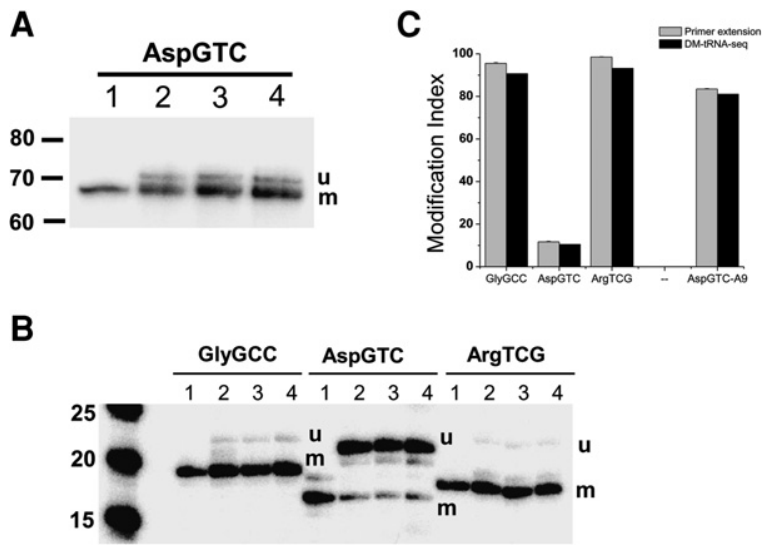

FIGURE 4. Validation of modification index by primer extension stops with AMV RT. All experiments were designed in such a way that the lower band corresponds to the amount of modified tRNA $(\mathrm{m})$ and the upper band the amount of unmodified tRNA (u); see Supplemental Figure S4. (Lane 1) Extension using only the respective $\alpha-{ }^{32} \mathrm{P}$-dNTP to indicate the product location. (Lanes 2-4) Extension from biological triplicates. (A) AspGTC for position 9, a putative $\mathrm{m}^{1} \mathrm{~A}$ identified in DM-tRNA-seq. (Lane 1) $a-{ }^{32} \mathrm{P}$-dCTP only; (lanes 2-4) dATP, $a-{ }^{32} \mathrm{P}-\mathrm{dCTP}$, ddGTP, dTTP. (B) GlyGCC, AspGTC, ArgTCG for position $\mathrm{m}^{1}$ A58. (Lanes 24 for GlyGCC and for AspGTC) $\alpha^{32}{ }^{32}$-dATP, dCTP, ddGTP, dTTP. (Lanes 2-4 for ArgTCG) ddATP, $a-{ }^{32} \mathrm{P}-\mathrm{dCTP}$, dGTP, dTTP. $(C)$ Quantitative comparison of modification fraction determined by primer extension (gray) and by DM-tRNA-seq (black). 
tRNA (Fig. 5E inset) still enables the analysis of $\mathrm{m}^{1} \mathrm{G} 9$ modification in mtTyr.

\section{Modification index heat maps for all abundant tRNAs}

We also show mutation and stop fractions across all tRNA isodecoders that are present in the top 25\% abundant tRNAs as heat maps (tRNA ${ }^{\text {Leu }}$ isodecoders in Fig. 6; tRNA isodecoders for other amino acids in Supplemental Fig. S7). To enhance presentation, all nucleotide positions in the heat map ( $x$ axis) are converted to standard tRNA nomenclature so that the anticodon nucleotides are always numbered $34-36, \mathrm{D}$ loop nucleotides 14-20, and variable loop nucleotides 4448. Human tRNA ${ }^{\mathrm{Leu}}$ 's contain five distinct isoacceptors with the anticodons of AAG, CAG, TAG, CAA, and TAA. In the mutation graph, the untreated samples show high mutation values at $\mathrm{m}^{1} \mathrm{~A} 58, \mathrm{~m}^{1} \mathrm{G} 37, \mathrm{~m}_{2}{ }_{2} \mathrm{G} 26$ for all isodecoders, $\mathrm{m}^{3} \mathrm{C} 47 \mathrm{~d}$ for the two CAG-isodecoders, and I for the two AAG-isodecoders. As expected, the $\mathrm{m}^{1} \mathrm{~A} 58, \mathrm{~m}^{1} \mathrm{G} 37$, and $\mathrm{m} 3 \mathrm{C} 47 \mathrm{~d}$ modifications are significantly reduced upon demethylase treatment. $\mathrm{M}^{1} \mathrm{G} 37$ and $\mathrm{m}_{2}^{2} \mathrm{G} 26$ also show significant stops in the untreated sample, but the stops are substantially reduced for $\mathrm{m}^{1} \mathrm{G} 37$, and moderately reduced for $\mathrm{m}_{2}^{2} \mathrm{G} 26$.

Applying the above criteria, all identified $\mathrm{m}^{1} \mathrm{~A}, \mathrm{~m}^{1} \mathrm{G}$, $\mathrm{m}_{2}^{2} \mathrm{G}$, and $\mathrm{m}^{3} \mathrm{C}$ sites in the tRNA transcriptome for 47 isoacceptors from HEK293T cells are shown in Table 1 (the remaining two annotated isoacceptors in the genomic tRNA database are excluded here because they are present at very low levels). They include 12/46 new $\mathrm{m}^{1} \mathrm{~A} 58$ (26\%), 4/15 new $\mathrm{m}^{1} \mathrm{G} 37$ (27\%), 10/25 new $\mathrm{m}_{2}{ }_{2} \mathrm{G}(40 \%), 6 / 21$ new $\mathrm{m}^{1} \mathrm{G} 9(29 \%)$, and $7 / 15$ new $\mathrm{m}^{3} \mathrm{C}(47 \%)$ sites not present in the human and other mammalian tRNAs in the Modomics database (Machnicka et al. 2013).

\section{rRNA modifications}

To extend the application of DM-RNA-seq, we applied it to sequence human rRNAs from HeLa cells. Human rRNA<smiles>Cn1cnc2c(=O)[nH]cnc21</smiles>

B

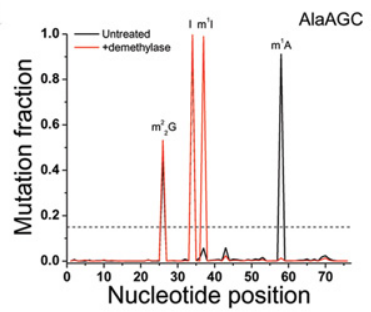

D

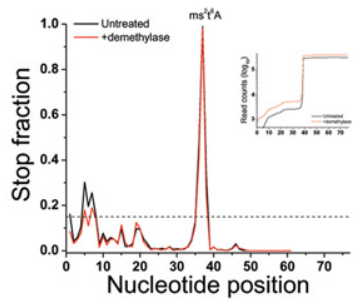

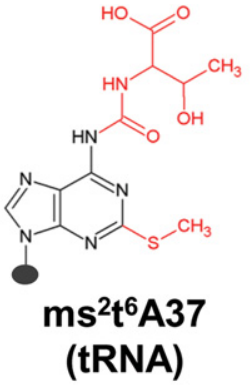

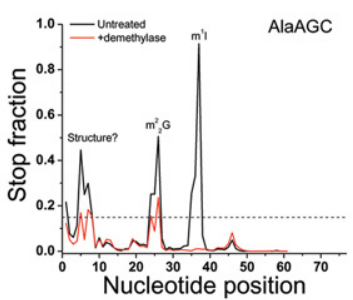

E

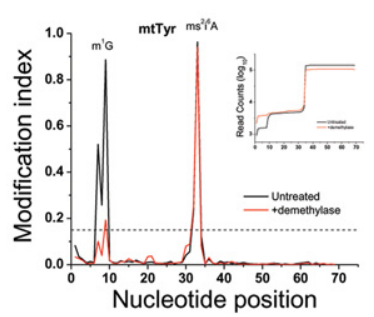

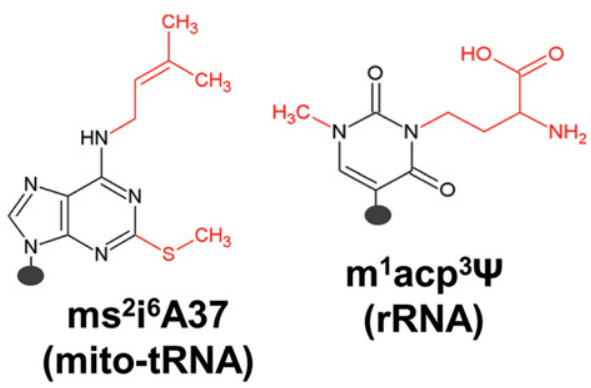

C

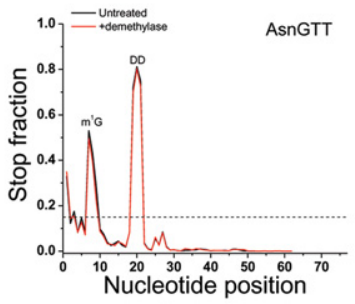

FIGURE 5. Plots for individual tRNAs with other methylations from DM-tRNA-seq. The MI value of these modifications does not change upon demethylase treatment. (A) Chemical structure of the five modifications where the chemical group is shown in red. The presence of each modification in tRNA and/or rRNA is listed beneath each base. (B) Mutation and stop plots showing AlaAGC with the known $\mathrm{m}^{1} \mathrm{I} 37$ and I34 modifications. (C)

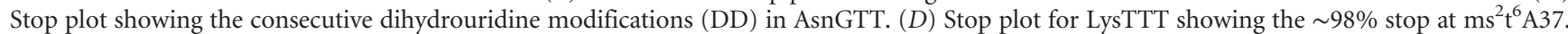
Inset ( $y$-axis $=\log _{10}$ counts along the LysTTT tRNA) shows that even with such strong stop, sufficient number of counts is still present for the analysis of modifications in this tRNA upstream of this stop. $(E)$ MI plot for mitochondrial tRNA ${ }^{\text {Tyr }}$ showing an $\sim 95 \%$ stop at $\mathrm{ms}^{2} \mathrm{i}^{6} \mathrm{~A} 37$. Inset $\left(y\right.$-axis $=\log _{10}$ counts along the mtTyr tRNA) shows that even with such strong stop, sufficient number of counts is still present for the analysis of the $\mathrm{m}^{1} \mathrm{G} 9 \mathrm{mod}$ ifications in this tRNA upstream of this stop. 

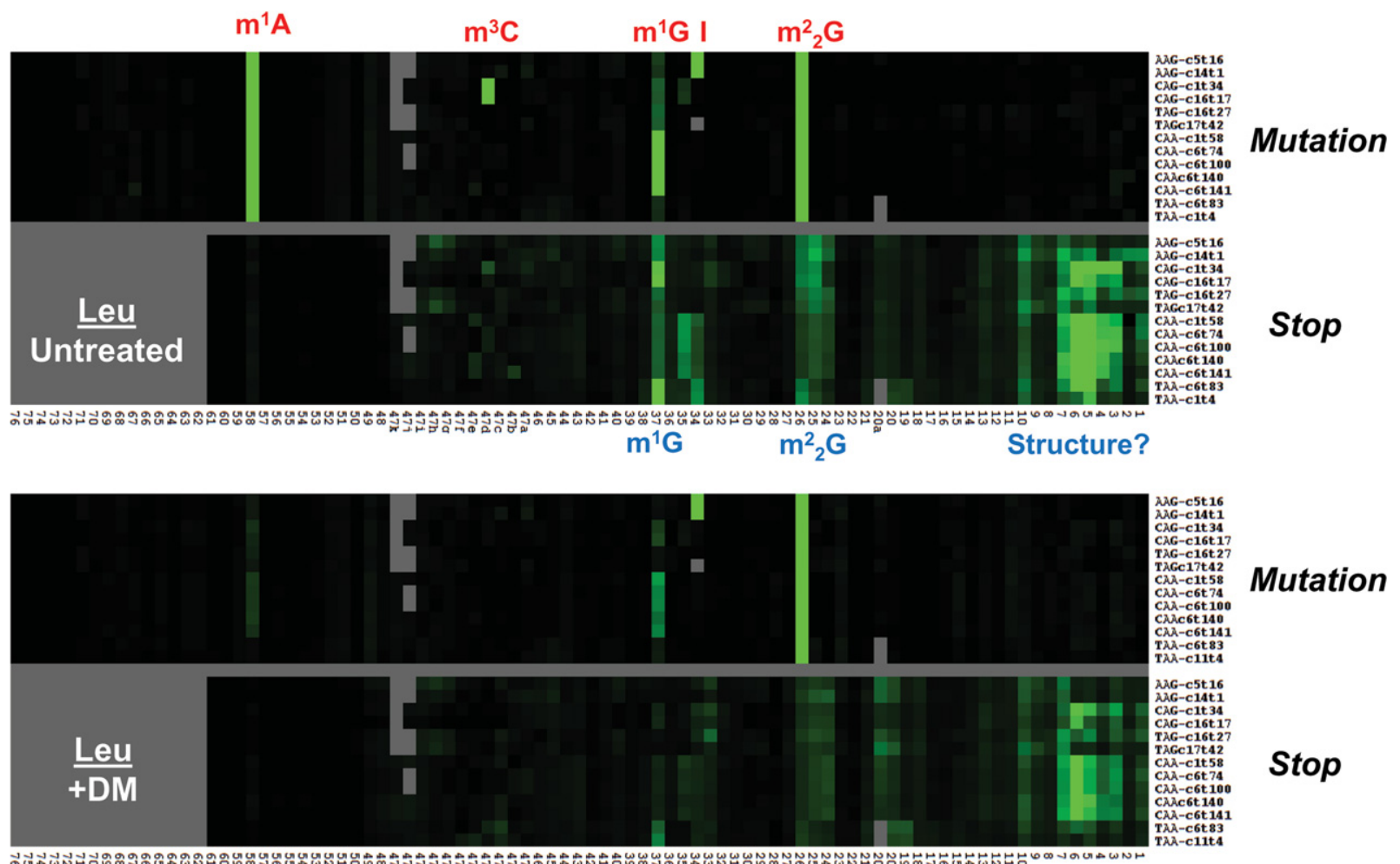

Mutation

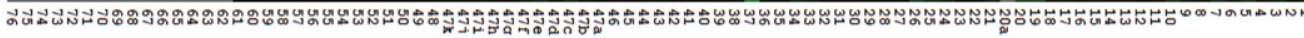
thi-chits

Stop

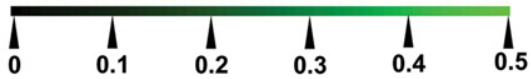

FIGURE 6. Mutation and stop heat maps for all abundant isodecoders in the tRNA ${ }^{\text {Leu }}$ family. The $x$-axis indicates the tRNA position according to the standard tRNA nomenclature so that the anticodons are always numbered 34-36, and the last nucleotide is always 76 . Nucleotides not present according to this nomenclature are shown in gray. Stops can only be analyzed up to nucleotide 61 so nucleotides $62-76$ are shown in gray. The scale of the heat map is shown on the lower left. Modifications are annotated in red or in blue according to their identification through mutation or stop component, respectively. Only the isodecoders that are among the top 25\% most abundant tRNA species are shown.

has four known modifications present at the Watson-Crick face of nucleobases: 1-methyl-3-(3-amino-3-carboxypropyl) pseudouridine ( $\mathrm{m}^{1} \mathrm{acp}^{3} \Psi$, Fig. 5A) and N6,N6-dimethyladenosine $\left(\mathrm{m}_{2}^{6} \mathrm{~A}\right)$ in the $18 \mathrm{~S} \mathrm{rNA}, \mathrm{m}^{1} \mathrm{~A}$ and 3-methyl uridine $\left(\mathrm{m}^{3} \mathrm{U}\right.$, Fig. $\left.1 \mathrm{~A}\right)$ in the $28 \mathrm{~S}$ rRNA. The DM-RNA-seq method was able to detect three of these modifications (Fig. 7). The $\mathrm{m}_{2}^{6} \mathrm{~A}$ site was not accessible in our present study because it is located 19 nt away from the $3^{\prime}$ end of $18 \mathrm{~S}$ rRNA, such
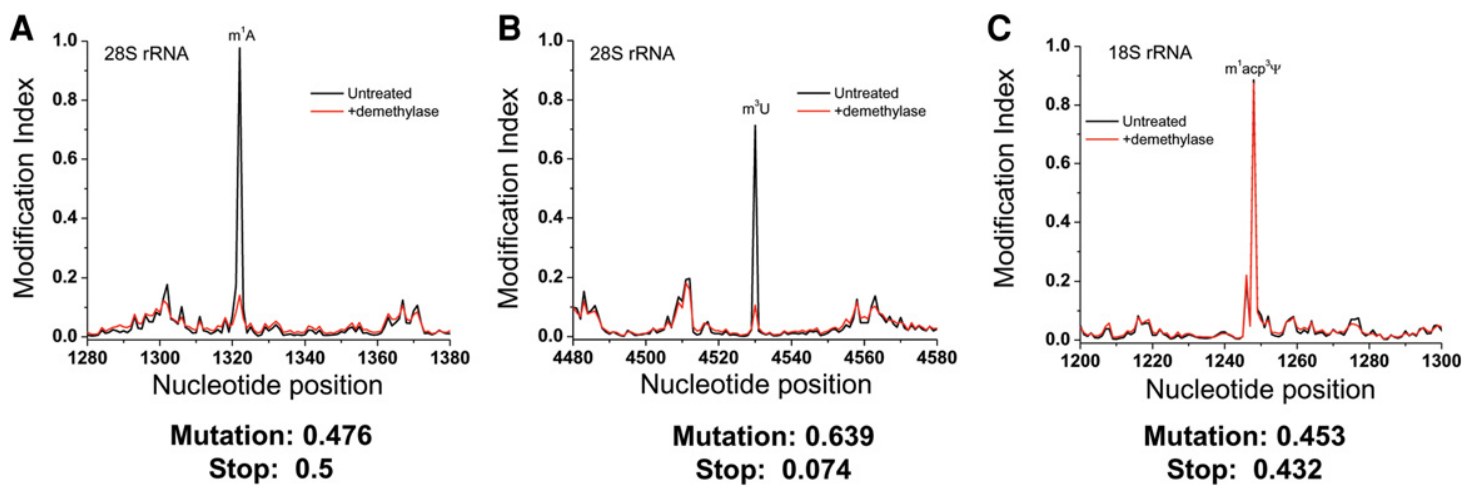

FIGURE 7. MI plots for rRNA modifications. (Black line) Untreated, (red line) demethylase-treated samples. The mutation and stop component of each modification is shown below the graph. (A) The $100 \mathrm{nt}$ region in the $28 \mathrm{~S}$ rRNA around $\mathrm{m}^{1} \mathrm{~A} 1322$. (B) The $100 \mathrm{nt}$ region in the $28 \mathrm{~S}$ rRNA around $\mathrm{m}^{3} \mathrm{U} 4530$. For both $A$ and $B$, demethylase treatment reduces the MI to background levels. $(C)$ The $100 \mathrm{nt}$ region in the $18 \mathrm{~S} \mathrm{rRNA} \operatorname{around}$ the $\mathrm{m}^{1}$ acp ${ }^{3}-$ $\Psi$ modification at 1248 . The black and red lines overlap, indicating that the demethylases do not act on this modification. 
that very short sequencing reads will be needed to obtain stop fraction. The $\mathrm{m}^{1} \mathrm{~A}$ site shows a very high MI value of 0.976 contributed about equally from mutations and stop; this high MI value is reduced to background levels upon demethylase treatment as expected (Fig. 7A). The rRNA $\mathrm{m}^{1} \mathrm{~A}$ result indicates that both mutations and stop can contribute significantly to the $\mathrm{m}^{1} \mathrm{~A}$ modification signature. The $\mathrm{m}^{3} \mathrm{U}$ site shows an MI value of 0.713 mostly derived from mutations; it is also reduced to background levels upon demethylase treatment (Fig. 7B), indicating that our demethylase mixture also acts on $m^{3} U$. The $m^{1} a c p^{3} \Psi$ site shows an MI value of 0.885 contributed about equally from mutations and stop; it does not respond to demethylase treatment (Fig. 7C).

Both the $\mathrm{m}^{1} \mathrm{~A}$ site in the $28 \mathrm{~S} \mathrm{rRNA}$ and the $\mathrm{m}^{1}$ acp ${ }^{3} \Psi$ site in the $18 \mathrm{~S}$ rRNA are previously known to be fully modified (Liang et al. 2009; Meyer et al. 2011). The very high MI values of $0.885-0.976$ at these two sites nicely reflect these high modification fractions.

\section{DISCUSSION}

This work demonstrates that RNA methylations at the Watson-Crick face can be precisely identified and importantly, their modification fractions assessed by the newly developed DM-tRNA-seq method. We show that the high extent of readthrough of the modifications by the thermophilic, group II intron RT (TGIRT) generates an adequate amount of reads to enable transcriptome-wide analysis of five tRNA and two rRNA methylations. The tRNA methylations we detect and assess quantitatively cover approximately onethird of all human tRNA modification sites. We were able to identify many previously known sites in the widely used RNA modification databases as well as new sites for which no prior experimental data exist. Examples of completely novel sites include the $\mathrm{m}^{3} \mathrm{C} 47 \mathrm{~d}$ site in LeuCAG and the $\mathrm{m}^{1} \mathrm{~A} 9$ in AspGTC, which we validated by sequencing-independent methods (Supplemental Figs. S4, S5).

Comparing the parallel sequenced, demethylase-treated and untreated data lends high confidence regarding the $\mathrm{m}^{1} \mathrm{~A}, \mathrm{~m}^{3} \mathrm{C}, \mathrm{m}^{1} \mathrm{G}$, and $\mathrm{m}^{2}{ }_{2} \mathrm{G}$ methylations that are widespread in the tRNA transcriptome. Interestingly, the particular mutation and stop patterns can also allow for initial assessment of the modification types for the same base such as $m^{1} G$ and $\mathrm{m}_{2}^{2} \mathrm{G}: \mathrm{m}^{1} \mathrm{G}$ is manifested by more significant stop than mutation fractions, whereas $\mathrm{m}_{2}^{2} \mathrm{G}$ is manifested by more mutation than stop signatures (Fig. 2B,C).

Of course, vast prior knowledge of these methylations in defined positions in many tRNAs significantly aided the validation and strengthening of our method. On the other hand, human tRNA modifications are still inadequately represented in the widely used modification databases such as Modomics and the RNA Modification Database (Cantara et al. 2011; Machnicka et al. 2013). Of the 47 human tRNA isoacceptors shown in Table 1, 11 do not have any data among the human and mammalian tRNAs, and 20 have data only among other mammalian tRNAs. Of the 22 human mitochondrial tRNAs shown in Table 2, 17 do not have data among the human mitochondrial tRNAs. Our results clearly help fill some of these large gaps.

A unique and new feature of our method is the use of the modification index (MI) to assess the quantitative nature of each detectable modification site. The MI values from DMtRNA-seq also correlate well with the classical primer extension stops using AMV RT for several $\mathrm{m}^{1} \mathrm{~A}$ sites (Fig. 4). The slightly lower modification fraction obtained in sequencing compared to primer extension stops may be explained by TGIRT inserting the "correct" base some of the time at the methylation sites. Furthermore, the MI values for $\mathrm{m}^{1} \mathrm{~A} 58$ in tRNAs likely underevaluated the $\mathrm{m}^{1} \mathrm{~A} 58$ modification fraction in this study due to the lack of stop information in our experimental design. As we have seen for the $\mathrm{m}^{1} \mathrm{~A} 9$ sites for mitochondrial tRNAs and the $\mathrm{m}^{1} \mathrm{~A} 1322$ site in rRNA, TGIRT does not read through $\mathrm{m}^{1} \mathrm{~A}$ all the time. In the future, the $\mathrm{m}^{1} \mathrm{~A} 58$ stop fraction should be obtained by using a longer TGIRT sequencing template for short RNA fragments derived from $\mathrm{m}^{1} \mathrm{~A} 58$ stops.

Surprisingly, we found that numerous methylation sites seem to fall into low and medium modified categories in the HEK293T tRNA transcriptome (Tables 1, 2). This result seems to suggest that dynamic ranges exist for tRNA methylations to have a cell-type and cell-state-dependent pattern. However, a confounding factor not investigated in detail here is the effect of sequence context of the modification site on the MI value. A recent work by Hauenschild et al. (2015) shows clear differences in mutation and stop fraction for $\mathrm{m}^{1} \mathrm{~A}$ with a different +1 nucleotide sequence, indicating that sequence context is an important parameter in determining the ration of mutations and stops at each site. Without additional studies of context dependence for each modification type and site, MI values cannot yet be fully used to precisely identify modification fractions. Despite these potential caveats, MI values can be interpreted as providing a lower bound on the modification fraction for each methylation site.

Biologically, quantitative differences in specific tRNA modifications have been well documented for the 5methoxycarbonylmethyl $\left(\mathrm{mcm}^{5}\right)$ and 5-methoxy-carbonyl-methyl-2-thio $\left(\mathrm{mcm}^{5} \mathrm{~s}^{2}\right)$ U34 modifications in tRNA $^{\text {Arg }}(\mathrm{UCU})$ and tRNA ${ }^{\text {Glu }}(\mathrm{UUC})$ and 5 -methyl $\left(\mathrm{m}^{5} \mathrm{C}\right)$ C34 in tRNA ${ }^{\text {Leu }}(\mathrm{CAA})$ to enhance stress response (Begley et al. 2007; Chan et al. 2012; Patil et al. 2012a,b). In yeast, global levels of many modification types such as $\mathrm{m}^{5} \mathrm{C}$, $\mathrm{m}_{2}^{2} \mathrm{G}$, and $2^{\prime} \mathrm{O}$-methyl-C $(\mathrm{Cm})$ can change significantly when cells are exposed to distinct types of chemical stressors (Chan et al. 2010; Gu et al. 2014).

In summary, using high-throughput DM-tRNA-seq data, we identified and semiquantified six base methylations and evaluated five other modifications in the human tRNA transcriptome and rRNA. Using the modification index metric, we assessed quantitative information on methylations at the 
Watson-Crick face among all isoacceptors in nuclear-encoded tRNAs and all mitochondrial-encoded tRNAs. While the functional investigation on the consequence of potential differences in modification fractions between cells is beyond the scope of this work, our result demonstrates the feasibility of using DM-tRNA-seq to investigate dynamic tRNA modification patterns.

\section{MATERIALS AND METHODS}

\section{DM-tRNA-seq of HEK293T and HeLa cells}

Experimental details of the DM-tRNA-seq method were described in Zheng et al. (2015). The same method was applied for HeLa rRNA sequencing except the input RNA was isolated rRNA that was subjected to chemical fragmentation before library preparation. Our DM-tRNA-seq data are composed of biological replicates of total tRNA from HEK293T cells without and with demethylase treatment. Both sets of replicates map with $r^{2} \geq 0.99$. For the analysis here, we used the untreated sample 2 which has 9,002,637 mapped reads to nuclear-encoded tRNA and 2,269,204 reads to mitochondrial-encoded tRNA, and treated sample 1 with 15,740,700 mapped reads to nuclear-encoded tRNA and 2,851,034 reads to mitochondrial-encoded tRNA. The rRNA-seq data contains 7,531,718 mapped reads.

\section{Sequencing alignments}

All reads were sequenced on an Illumina HiSeq 2000 with pairedend mapping with read lengths of 100 base pairs. Standard quality control via FastQC was performed after sequencing and after subsequent trimming mentioned next.

Sequencing reads were aligned using Bowtie to a modified tRNA genome file containing nuclear-encoded tRNAs, mitochondrially encoded tRNAs, and human rRNAs (found at the GEO accession for this paper). Splicing of tRNAs was accounted for in the modified genome file and only mature tRNAs were aligned against. Briefly, the tRNA library was adapted from the tRNAScan-SE library (http :/gtrnadb.ucsc.edu/Hsapi19/; Chan and Lowe 2009) by appending $3^{\prime} \mathrm{CCA}$ to tRNAs from the genomic tRNA database. Isodecoders with identical SEscan scores from the genomic tRNA database were consolidated for ease of identity assignment, so the total number of annotated tRNA genes and pseudogenes were reduced from 625 to 462 . Prior to mapping, reads were processed using Trimmomatic v0.32 as well as further trimming using custom Python scripts to remove any further artifacts from demultiplexing and removal of primers, adapters, or any other low-quality sequences. Sequences $>15$ bp were then aligned to the library using Bowtie 1.0 with sensitive options using the highest allowed mismatch settings for Bowtie 1.0. Mapping to all references occurred simultaneously. Only one alignment (best with Bowtie1 or $k=1$ with Bowtie2, $k$ refers to the number of allowed distinct alignments per raw read) declared as valid by the respective mapping software was reported for each read. Analysis was also performed using $k=3$ to allow for up to three alignments per read and also $v=0,1,2,3$ (how many mismatches allowed in the seed sequence per raw read) in Bowtiel to allow for fewer mismatches.

\section{Modification index (MI)}

The mapping pipeline proceeded by conversion from the SAM output from Bowtie using custom $\mathrm{C}$ and Python scripts to separate isodecoders based on previous alignment. From here, further cleanup based on redundancy (any read that could inherently map due to misalignment) was also discarded. For each position in the reference file, the following was calculated: at each position $=n$, how many counts existed (total counts) $=c$, how many misincorporations or mutations $=m$, and how many aligned reads stopped at the position $=s$. This leads to a full modification index (MI) calculated at each position by (mutations at position + stops at position directly $3^{\prime}$ to position $) /($ total counts at position $)$, or $(m+s) / c$, and individual mutation and stop components to the metric can be further reduced by calculating $\mathrm{m} / \mathrm{c}$ and $\mathrm{s} / \mathrm{c}$, respectively.

For high stringency detection purposes for this work, sites corresponding to an MI value of $15 \%$ or below were discarded as noise due to sequencing error or basal level of misincorporation from the RT reaction. For simplicity and ease of discussion, sites with $\mathrm{MI} \geq 15 \%$ were categorized in the range of $15 \%-50 \%$ as low, $50 \%-80 \%$ as medium, and $80 \%-100 \%$ as highly or completely modified. Positional shifts of modifications due to tRNA length (either due to variations in length of type I tRNAs or type I versus type II tRNAs) were recognized and adjusted for in calculations for heat maps. Modification index in regions of variable loop are accounted for accordingly. Modification index $3^{\prime}$ to $\mathrm{m}^{1} \mathrm{~A} 57 / 58 / 59 / 68$ ( $\mathrm{m}^{1} \mathrm{~A} 58$ in standard tRNA nomenclature) is only derived from mutations due to the lack of stop information at these positions because of the short reads needed for stops at this $\mathrm{m}^{1} \mathrm{~A}$ position.

\section{Reverse transcription primer extension}

Total RNA was isolated from HEK293T cells in biological triplicates using TRIzol (Life Technologies). tRNA was gel purified by $8 \%$ denaturing PAGE (7M urea, $1 \times \mathrm{TBE}$ ). Seven hundred nanograms of total RNA or $200 \mathrm{ng}$ of total tRNA was annealed to 5 pmol of specific primer in $30 \mathrm{mM}$ Tris- $\mathrm{Cl}(\mathrm{pH} 7.5), 2 \mathrm{mM} \mathrm{KCl}$ at $90^{\circ} \mathrm{C}$ for 90 sec. The mixture was cooled at room temperature for $3 \mathrm{~min}$. The reverse transcription reaction was carried out in $1 \times$ AMV buffer, 0.1 $\mathrm{mM}$ each cold (d)dNTP, $1.25 \mu \mathrm{M}$ radiolabeled dNTP, and $0.2 \mathrm{U} /$ $\mu \mathrm{L}$ AMV RT (New England Biolabs). The reaction was performed at $37^{\circ} \mathrm{C}$ for $30 \mathrm{~min}$. To degrade the RNA after the RT reaction, 10 $\mathrm{U}$ of $\mathrm{RNaseH}$ (Epicentre) was added, and the reaction was incubated at $37^{\circ} \mathrm{C}$ for $5 \mathrm{~min}$. RNA loading dye ( $9 \mathrm{M}$ urea, $100 \mathrm{mM} \mathrm{Na}_{2}$ EDTA, bromophenol blue, xylene cyanol) was added and the reaction was resolved by denaturing gels $(7 \mathrm{M}$ urea, $1 \times \mathrm{TBE})$.

\section{Validation of $m^{1} \mathrm{~A} 9$ in tRNA ${ }^{\text {Asp }}$ (AspGTC) and $m^{3} \mathrm{C} 47 \mathrm{~d}$ in tRNA ${ }^{\text {Leu }}$ (LeuCAG)}

Total RNA was isolated from HEK293T cells using TRIzol (Life Technologies). Total tRNA was gel purified by $8 \%$ denaturing PAGE (7 M urea, $1 \times$ TBE).

RNase $H$ cleavage and fragment isolation

For AspGTC, $5^{\prime}{ }^{32} \mathrm{P}$-labeled tRNA was spiked into $20 \mu \mathrm{g}$ of total tRNA and annealed to 20 pmol DNA oligo (5'-TGGCTCCCCGT CGGGGAATCGAACCCCGGTCTCCCGCGTGACAGGCGGGG) 
complementary to nucleotides 26-76. For LeuCAG, $3^{\prime}{ }^{32} \mathrm{P}$-labeled tRNA was spiked into $20 \mu \mathrm{g}$ of total tRNA and annealed to 20 pmol DNA oligo (5'-CTGCGACCTGAACGCAGCGCCTTAGA CCGCTCGGCCATCCTGAC) complementary to nucleotides 142. The tRNA/oligo was annealed in $100 \mathrm{mM}$ Tris- $\mathrm{HCl}(\mathrm{pH} 7.5)$, $0.5 \mathrm{mM}$ EDTA at $90^{\circ} \mathrm{C}$ for $90 \mathrm{sec}$. The reaction was cooled at room temperature for $3 \mathrm{~min}$. Digestion was performed by adding $\mathrm{NaCl}$ to $100 \mathrm{mM}, \mathrm{MgCl}_{2}$ to $10 \mathrm{mM}$, and RNase $\mathrm{H}$ (Epicenter) to a final concentration of $1 \mathrm{U} / \mu \mathrm{L}$. The reaction was incubated at $37^{\circ}$ $\mathrm{C}$ for $30 \mathrm{~min} .0 .1 \mathrm{U} / \mu \mathrm{L}$ DNase I (NEB) was added and the reaction was incubated at $37^{\circ} \mathrm{C}$ for $30 \mathrm{~min}$. The reaction was then ethanol precipitated, resuspended in $1 \times$ RNA loading dye $(4.5 \mathrm{M}$ urea, $50 \mathrm{mM}$ EDTA), and resolved on 10\% denaturing PAGE (7 M urea, $1 \times \mathrm{TBE})$. The digestion products were eluted in $200 \mathrm{mM}$ $\mathrm{NH}_{4} \mathrm{Cl}, 50 \mathrm{mM} \mathrm{NH} \mathrm{N}_{4} \mathrm{OAc}$ overnight. Glycogen was added to aid precipitation.

\section{MALDI-TOF}

Approximately 2 pmol of eluted fragements was digested with $0.5 \mathrm{U} /$ $\mu \mathrm{L} \mathrm{T} 1$ (Ambion) in $10 \mathrm{mM} \mathrm{NH}_{4} \mathrm{OAc}$ for $30 \mathrm{~min}$ at $37^{\circ} \mathrm{C}$. One pico mole of the digested fragments was mixed with an equal amount of MALDI matrix, composed by 9:1 (v:v) ratio of 20-, 40-, 60-trihydroxyacetophenone (THAP, $10 \mathrm{mg} / \mathrm{mL}$ in $50 \% \mathrm{CH}_{3} \mathrm{CN} / \mathrm{H}_{2} \mathrm{O}$ ): diammonium citrate $\left(50 \mathrm{mg} / \mathrm{mL}\right.$ in $\left.\mathrm{H}_{2} \mathrm{O}\right)$. The mixture was spotted on a MALDI sample plate, dried under vacuum, and analyzed by a Bruker Ultra-flextreme MALDI-TOF Mass Spectrometer in reflector, positive mode.

\section{LC/MS-QQQ}

Approximately 1 pmol of RNase T1-digested fragments was digested with nuclease $\mathrm{P} 1$ in $100 \mathrm{mM}$ ammonium acetate at $37^{\circ} \mathrm{C}$ for 2 h. Three microliters of freshly prepared $1 \mathrm{M}$ ammonium carbonate was added with $1 \mathrm{U}$ of alkaline phosphatase (Roche) and further incubated at $37^{\circ} \mathrm{C}$ for $2 \mathrm{~h}$. Mixture was centrifuged through a $0.22 \mathrm{~m}$ PVDF syringe filter (Millex-GV) to remove contaminants. Remaining sample was then separated by reverse phase ultra-performance liquid chromatography (RP-UPLC) on a C18 column (Agilent's ZORBAX Eclipse XDB-C18, Rapid Resolution HT, $2.1 \times 50 \mathrm{~mm}, 1.8 \mu \mathrm{m}$, max 600 bar; mobile phase A: water $+0.1 \%$ (v/v) formic acid, mobile phase B: methanol $+0.1 \%(\mathrm{v} / \mathrm{v})$ formic acid, with a gradient of $2 \%-11 \% \mathrm{~B}$ in $4.5 \mathrm{~min}$ ) with on-line mass spectrometry detection using an Agilent 6460 triple-quadrupole (QQQ) mass spectrometer in positive electrospray ionization mode. The nucleosides were identified via dynamic multiple reaction monitoring (DMRM) by using the nucleoside-to-base ion mass transitions of $282-150\left(\mathrm{~m}^{1} \mathrm{~A}\right)$ and $258-126\left(\mathrm{~m}^{3} \mathrm{C}\right)$.

\section{Hydrazine/analine cleavage and tRNA microarray}

$3^{\prime 32} \mathrm{P}$-labeled tRNA was spiked into $0.2 \mu \mathrm{g} / \mu \mathrm{L}$ total tRNA and incubated with $10 \%$ hydrazine in $3 \mathrm{M} \mathrm{NaCl}$ at $4^{\circ} \mathrm{C}$ for $10 \mathrm{~min}$, quenched with $0.3 \mathrm{M} \mathrm{NaOAc/HOAc}, \mathrm{pH} 5.5$, and ethanol precipitated. The pellet was then resuspended in $1 \mathrm{M}$ aniline, $1 \mathrm{M} \mathrm{HOAc}$. The reaction was incubated at $60^{\circ} \mathrm{C}$ for $10 \mathrm{~min}$, quenched with $0.3 \mathrm{M} \mathrm{NaOAc/}$ HOAc, pH 5.5, and ethanol precipitated. The pellet was resuspended in $1 \times$ RNA loading buffer (4.5 M urea, $50 \mathrm{mM}$ EDTA) and resolved on $15 \%$ denaturing PAGE ( $7 \mathrm{M}$ urea, $1 \times \mathrm{TBE}$ ). Fragments were eluted in $200 \mathrm{mM} \mathrm{KCl}, 50 \mathrm{mM}$ KOAc overnight. Poly(A) RNA and salmon sperm DNA were added to aid in precipitation. The frag- ments were then hybridized to custom-made tRNA microarrays at $60^{\circ} \mathrm{C}$ for $16 \mathrm{~h}$ and exposed to phosphorimaging as previously described (Parisien et al. 2013).

\section{DATA DEPOSITION}

DM-tRNA-seq data are from GSE66550. The rRNA-seq data with and without demethylase treatment are from GSE76434.

\section{SUPPLEMENTAL MATERIAL}

Supplemental material is available for this article

\section{ACKNOWLEDGMENTS}

We thank Dr. Qing Dai for his guidance in MALDI experiments. This work was supported by the National Institutes of Health (DP1GM105386 to T.P.). W.C.C. and M.E.E. were recipients of a National Institutes of Health Chemistry and Biology Training grant (T32 GM008720). M.E.E. is a recipient of the National Science Foundation predoctoral fellowship (DGE-1144082).

Received March 7, 2016; accepted August 12, 2016.

\section{REFERENCES}

Begley U, Dyavaiah M, Patil A, Rooney JP, DiRenzo D, Young CM, Conklin DS, Zitomer RS, Begley TJ. 2007. Trm9-catalyzed tRNA modifications link translation to the DNA damage response. Mol Cell 28: 860-870.

Behm-Ansmant I, Helm M, Motorin Y. 2011. Use of specific chemical reagents for detection of modified nucleotides in RNA. J Nucleic Acids 2011: 408053.

Bjork GR, Wikstrom PM, Bystrom AS. 1989. Prevention of translational frameshifting by the modified nucleoside 1-methylguanosine. Science 244: 986-989.

Cantara WA, Crain PF, Rozenski J, McCloskey JA, Harris KA, Zhang X, Vendeix FA, Fabris D, Agris PF. 2011. The RNA modification database, RNAMDB: 2011 update. Nucleic Acids Res 39: D195-D201.

Chan PP, Lowe TM. 2009. GtRNAdb: a database of transfer RNA genes detected in genomic sequence. Nucleic Acids Res 37: D93-D97.

Chan JC, Yang JA, Dunn MJ, Agris PF, Wong TW. 1982. The nucleotide sequence of a glutamate tRNA from rat liver. Nucleic Acids Res 10: 4605-4608.

Chan CT, Dyavaiah M, DeMott MS, Taghizadeh K, Dedon PC, Begley TJ. 2010. A quantitative systems approach reveals dynamic control of tRNA modifications during cellular stress. PLoS Genet 6: e1001247.

Chan CT, Pang YL, Deng W, Babu IR, Dyavaiah M, Begley TJ, Dedon PC. 2012. Reprogramming of tRNA modifications controls the oxidative stress response by codon-biased translation of proteins. Nat Commun 3: 937.

Cozen AE, Quartley E, Holmes AD, Hrabeta-Robinson E, Phizicky EM, Lowe TM. 2015. ARM-seq: AlkB-facilitated RNA methylation sequencing reveals a complex landscape of modified tRNA fragments. Nat Methods 12: 879-884.

Dalluge JJ, Hashizume T, Sopchik AE, McCloskey JA, Davis DR. 1996. Conformational flexibility in RNA: the role of dihydrouridine. Nucleic Acids Res 24: 1073-1079.

Decatur WA, Fournier MJ. 2002. rRNA modifications and ribosome function. Trends Biochem Sci 27: 344-351. 
Dominissini D, Moshitch-Moshkovitz S, Schwartz S, Salmon-Divon M, Ungar L, Osenberg S, Cesarkas K, Jacob-Hirsch J, Amariglio N, Kupiec M, et al. 2012. Topology of the human and mouse m6A RNA methylomes revealed by m6A-seq. Nature 485: 201-206.

Dominissini D, Nachtergaele S, Moshitch-Moshkovitz S, Peer E, Kol N, Ben-Haim MS, Dai Q, Di Segni A, Salmon-Divon M, Clark WC, et al. 2016. The dynamic $N^{1}$-methyladenosine methylome in eukaryotic messenger RNA. Nature 530: 441-446.

Edqvist J, Straby KB, Grosjean H. 1995. Enzymatic formation of N2,N2dimethylguanosine in eukaryotic tRNA: importance of the tRNA architecture. Biochimie 77: 54-61.

Fu Y, Dominissini D, Rechavi G, He C. 2014. Gene expression regulation mediated through reversible $\mathrm{m}^{6} \mathrm{~A}$ RNA methylation. Nat Rev Genet 15: 293-306.

Gamper HB, Masuda I, Frenkel-Morgenstern M, Hou YM. 2015. Maintenance of protein synthesis reading frame by EF-P and $\mathrm{m}^{1} \mathrm{G} 37$-tRNA. Nat Commun 6: 7226.

Gerber AP, Keller W. 1999. An adenosine deaminase that generates inosine at the wobble position of tRNAs. Science 286: 1146-1149.

Goodenbour JM, Pan T. 2006. Diversity of tRNA genes in eukaryotes. Nucleic Acids Res 34: 6137-6146.

Grosjean H. 2005. Modification and editing of RNA: historical overview and important facts to remember. In Fine-tuning of RNA functions by modification and editing (ed. Grosjean H), Vol. 12, pp. 1-22. Springer, Berlin/Heidelberg, Germany.

Grosjean H, Auxilien S, Constantinesco F, Simon C, Corda Y, Becker HF, Foiret D, Morin A, Jin YX, Fournier M, et al. 1996. Enzymatic conversion of adenosine to inosine and to N1-methylinosine in transfer RNAs: a review. Biochimie 78: 488-501.

Gu C, Begley TJ, Dedon PC. 2014. tRNA modifications regulate translation during cellular stress. FEBS Lett 588: 4287-4296.

Hauenschild R, Tserovski L, Schmid K, Thuring K, Winz ML, Sharma S, Entian KD, Wacheul L, Lafontaine DL, Anderson J, et al. 2015. The reverse transcription signature of N-1-methyladenosine in RNA-seq is sequence dependent. Nucleic Acids Res 43: 9950-9964.

Helm M, Giege R, Florentz C. 1999. A Watson-Crick base-pair-disrupting methyl group (m1A9) is sufficient for cloverleaf folding of human mitochondrial tRNA ${ }^{\text {Lys }}$. Biochemistry 38: 13338-13346.

Higa-Nakamine S, Suzuki T, Uechi T, Chakraborty A, Nakajima Y, Nakamura M, Hirano N, Kenmochi N. 2012. Loss of ribosomal RNA modification causes developmental defects in zebrafish. Nucleic Acids Res 40: 391-398.

Kadaba S, Krueger A, Trice T, Krecic AM, Hinnebusch AG, Anderson J. 2004. Nuclear surveillance and degradation of hypomodified initiator tRNA ${ }^{\text {Met }}$ in S. cerevisiae. Genes Dev 18: 1227-1240.

Kuchino Y, Shindo-Okada N, Ando N, Watanabe S, Nishimura S. 1981. Nucleotide sequences of two aspartic acid tRNAs from rat liver and rat ascites hepatoma. J Biol Chem 256: 9059-9062.

Li S, Mason CE. 2014. The pivotal regulatory landscape of RNA modifications. Annu Rev Genomics Hum Genet 15: 127-150.

Li X, Xiong X, Wang K, Wang L, Shu X, Ma S, Yi C. 2016. Transcriptome-wide mapping reveals reversible and dynamic Nmethyladenosine methylome. Nat Chem Biol 12: 311-316.

Liang XH, Liu Q, Fournier MJ. 2009. Loss of rRNA modifications in the decoding center of the ribosome impairs translation and strongly delays pre-rRNA processing. RNA 15: 1716-1728.

Machnicka MA, Milanowska K, Osman Oglou O, Purta E, Kurkowska M, Olchowik A, Januszewski W, Kalinowski S, DuninHorkawicz S, Rother KM, et al. 2013. MODOMICS: a database of RNA modification pathways-2013 update. Nucleic Acids Res 41: D262-D267.
Meyer B, Wurm JP, Kotter P, Leisegang MS, Schilling V, Buchhaupt M, Held M, Bahr U, Karas M, Heckel A, et al. 2011. The Bowen-Conradi syndrome protein Nep1 (Emg1) has a dual role in eukaryotic ribosome biogenesis, as an essential assembly factor and in the methylation of $\Psi 1191$ in yeast 18S rRNA. Nucleic Acids Res 39: 1526-1537.

Meyer KD, Saletore Y, Zumbo P, Elemento O, Mason CE, Jaffrey SR. 2012. Comprehensive analysis of mRNA methylation reveals enrichment in $3^{\prime}$ UTRs and near stop codons. Cell 149: 1635-1646.

Motorin Y, Muller S, Behm-Ansmant I, Branlant C. 2007. Identification of modified residues in RNAs by reverse transcription-based methods. Methods Enzymol 425: 21-53.

Ohira T, Suzuki T. 2011. Retrograde nuclear import of tRNA precursors is required for modified base biogenesis in yeast. Proc Natl Acad Sci 108: 10502-10507.

Pallan PS, Kreutz C, Bosio S, Micura R, Egli M. 2008. Effects of N2,N2dimethylguanosine on RNA structure and stability: crystal structure of an RNA duplex with tandem $\mathrm{m}^{2}{ }_{2} \mathrm{G}$ :A pairs. RNA 14: 2125-2135.

Parisien M, Wang X, Perdrizet G II, Lamphear C, Fierke CA, Maheshwari KC, Wilde MJ, Sosnick TR, Pan T. 2013. Discovering RNA-protein interactome by using chemical context profiling of the RNA-protein interface. Cell Rep 3: 1703-1713.

Patil A, Chan CT, Dyavaiah M, Rooney JP, Dedon PC, Begley TJ. 2012a. Translational infidelity-induced protein stress results from a deficiency in Trm9-catalyzed tRNA modifications. RNA Biol 9: 990-1001.

Patil A, Dyavaiah M, Joseph F, Rooney JP, Chan CT, Dedon PC, Begley TJ. 2012b. Increased tRNA modification and gene-specific codon usage regulate cell cycle progression during the DNA damage response. Cell Cycle 11: 3656-3665.

Peattie DA. 1979. Direct chemical method for sequencing RNA. Proc Natl Acad Sci 76: 1760-1764.

Phizicky EM, Hopper AK. 2010. tRNA biology charges to the front. Genes Dev 24: 1832-1860.

Ryvkin P, Leung YY, Silverman IM, Childress M, Valladares O, Dragomir I, Gregory BD, Wang LS. 2013. HAMR: high-throughput annotation of modified ribonucleotides. RNA 19: 1684-1692.

Saikia M, Fu Y, Pavon-Eternod M, He C, Pan T. 2010. Genome-wide analysis of N1-methyl-adenosine modification in human tRNAs. RNA 16: 1317-1327.

Steinberg S, Cedergren R. 1995. A correlation between N2-dimethylguanosine presence and alternate tRNA conformers. RNA 1: 886-891.

Suzuki T, Suzuki T. 2014. A complete landscape of post-transcriptional modifications in mammalian mitochondrial tRNAs. Nucleic Acids Res 42: 7346-7357.

Vinayak M, Pathak C. 2010. Queuosine modification of tRNA: its divergent role in cellular machinery. Biosci Rep 30: 135-148.

Wei FY, Suzuki T, Watanabe S, Kimura S, Kaitsuka T, Fujimura A, Matsui H, Atta M, Michiue H, Fontecave M, et al. 2011. Deficit of tRNA $^{\text {Lys }}$ modification by Cdkall causes the development of type 2 diabetes in mice. J Clin Invest 121: 3598-3608.

Whipple JM, Lane EA, Chernyakov I, D’Silva S, Phizicky EM. 2011. The yeast rapid tRNA decay pathway primarily monitors the structural integrity of the acceptor and T-stems of mature tRNA. Genes Dev 25: 1173-1184.

Zaborske JM, DuMont VL, Wallace EW, Pan T, Aquadro CF, Drummond DA. 2014. A nutrient-driven tRNA modification alters translational fidelity and genome-wide protein coding across an animal genus. PLoS Biol 12: e1002015.

Zheng G, Qin Y, Clark WC, Dai Q, Yi C, He C, Lambowitz AM, Pan T. 2015. Efficient and quantitative high-throughput tRNA sequencing. Nat Methods 12: 835-837. 

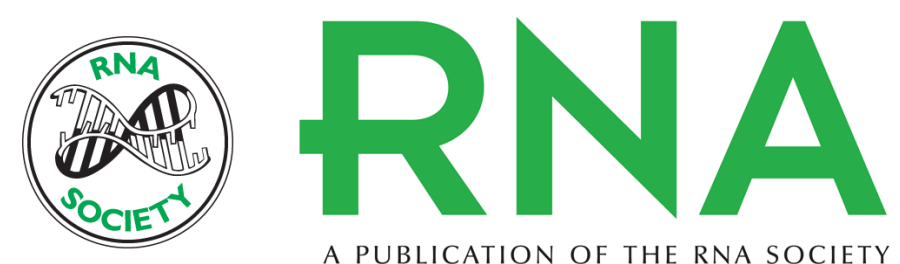

A PUBLICATION OF THE RNA SOCIETY

\section{tRNA base methylation identification and quantification via high-throughput sequencing}

Wesley C. Clark, Molly E. Evans, Dan Dominissini, et al.

RNA 2016 22: 1771-1784 originally published online September 9, 2016

Access the most recent version at doi:10.1261/rna.056531.116

\section{Supplemental http://rnajournal.cshlp.org/content/suppl/2016/09/09/rna.056531.116.DC1 Material}

References This article cites 49 articles, 14 of which can be accessed free at: http://rnajournal.cshlp.org/content/22/11/1771.full.html\#ref-list-1

Creative This article is distributed exclusively by the RNA Society for the first 12 months after the Commons License full-issue publication date (see http://rnajournal.cshlp.org/site/misc/terms.xhtml). After 12 months, it is available under a Creative Commons License (Attribution-NonCommercial 4.0 International), as described at http://creativecommons.org/licenses/by-nc/4.0/.

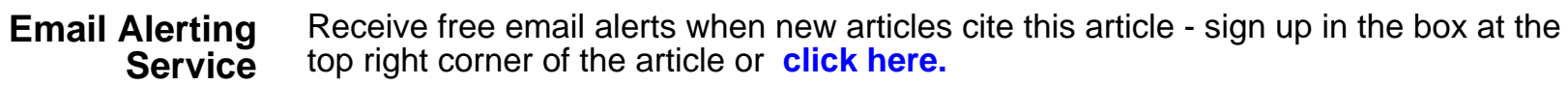

